\title{
Adaptive Vibration Control System for MR Damper Faults
}

\author{
Juan C. Tudón-Martínez and Ruben Morales-Menendez \\ Tecnológico de Monterrey, Escuela de Ingeniería y Ciencias, Avenida Garza Sada No. 2501, 64849 Monterrey, NL, Mexico \\ Correspondence should be addressed to Juan C. Tudón-Martínez; jc.tudon.phd.mty@itesm.mx
}

Received 30 January 2015; Revised 29 April 2015; Accepted 4 May 2015

Academic Editor: Miao Yu

Copyright (C) 2015 J. C. Tudón-Martínez and R. Morales-Menendez. This is an open access article distributed under the Creative Commons Attribution License, which permits unrestricted use, distribution, and reproduction in any medium, provided the original work is properly cited.

\begin{abstract}
Several methods have been proposed to estimate the force of a semiactive damper, particularly of a magnetorheological damper because of its importance in automotive and civil engineering. Usually, all models have been proposed assuming experimental data in nominal operating conditions and some of them are estimated for control purposes. Because dampers are prone to fail, fault estimation is useful to design adaptive vibration controllers to accommodate the malfunction in the suspension system. This paper deals with the diagnosis and estimation of faults in an automotive magnetorheological damper. A robust LPV observer is proposed to estimate the lack of force caused by a damper leakage in a vehicle corner. Once the faulty damper is isolated in the vehicle and the fault is estimated, an Adaptive Vibration Control System is proposed to reduce the fault effect using compensation forces from the remaining healthy dampers. To fulfill the semiactive damper constraints in the fault adaptation, an LPV controller is designed for vehicle comfort and road holding. Simulation results show that the fault observer has good performance with robustness to noise and road disturbances and the proposed AVCS improves the comfort up to $24 \%$ with respect to a controlled suspension without fault tolerance features.
\end{abstract}

\section{Introduction}

In general, a damper is characterized by [1] (a) the dimensional data, (b) operating factors, and (c) force characteristics. Dimensional data include the stroke, the length between mountings, diameters, and weight. Operating factors include the limitations on temperature, power dissipation, and cooling requirements, while the most fundamental characteristics are the magnitude and shape of the force; that is, force characteristics indicate how the force varies with respect to the velocity, production tolerances on these forces, friction effects, saturation, and so forth. When the damper fails, the force characteristics are modified.

According to the capability to adjust the force characteristics, the automobile dampers can be classified as passive, active, or semiactive. Passive dampers are only able to dissipate the energy and their damping characteristics are time invariant, while active ones are able to store, dissipate, and generate energy through a variable damping coefficient, but they are very expensive to apply because they require an external power supply. Semiactive dampers represent a good solution to control the vertical vehicle dynamics using lower energy consumption and lower cost [2]. Different semiactive damper technologies have been examined, whose bandwidth oscillates from 0 to $30 \mathrm{~Hz}$; the main technologies in the automotive industry are electrohydraulic dampers (EH), pneumatic actuators (PA), and magneto/electrorheological dampers (MR/ER).

In an automotive suspension control system, the damping force on a controllable shock absorber is adjusted to improve the comfort and/or safety of the passengers in a road vehicle, overcoming the weaknesses of passive suspensions. Because the cost-benefit ratio is better in semiactive suspensions than in active ones, the major interest of the control community related to automotive suspensions is focused on the semiactive suspension control. An extensive classification of different control strategies for semiactive dampers according to the type of manipulation (continuous or on-off), control goal (comfort, road holding, or both), type of control law to include the semiactiveness (clipped, frequency adaptive, frequency switched, and measurement-based), type of control design (model-based or free of model), and so forth is 
presented in [3]. Indeed, without considering the nature of the control strategy, the interesting challenges of the semiactive suspension control problem are as follows [4]:

(1) Realistic design according to the nonlinearities of the semiactive damper.

(2) Constrained control according to the dissipativity and saturation of the damper to avoid impractical solutions, even if this actuator is partially faulty.

(3) Multiobjective control design, that is, capable of improving the vehicle comfort with no compromise (and perhaps enhancement) for the road holding.

(4) Feasibility of implementation: with adaptation to different damper technologies, small number of control inputs, and low computing cost to be programmed in microcontrollers.

An extensive work on semiactive suspension systems emphasizes that MR dampers are one of the best solutions to manage the compromise between the objectives of an automotive suspension control: comfort and road holding. $\mathrm{MR}$ dampers are as fast as the $\mathrm{EH}$ actuators with less power requirement than ER dampers and higher robustness to temperature variations; they are easier to manufacture and implement than EH dampers and to control than PA. Indeed, most of the existing work on semiactive damper modeling and control is based on the MR damping technology [1].

Several mathematical models are available to represent the nonlinear behavior of MR dampers. In general, they can be grouped as parametric and nonparametric models. Parametric models explain the physical phenomena in mathematical expressions, for instance, the classical viscoelasticplastic models $[5,6]$, the phenomenological evolutive BoucWen models [7-12], and the algebraic models [13-15]. On the other hand, coefficients of nonparametric structures do not have a physical meaning, for instance, fuzzy models [16, 17], statistical models [18], polynomial models [19-22], or models based on artificial neural networks (ANN) [23-29]. Usually, all aforementioned structures have presented good modeling results and/or good properties to design control modules; but when the damper is faulty, nothing can be said.

The most common fault in MR dampers is oil leakage [1]. There are different aspects that cause a damper leakage [30], which are related to bad installation, excessive use, damage by external devices, or bad design of control system that saturates the manipulation. The direct consequence of a faulty shock absorber is the loss of damping force that causes a performance reduction in the suspension capabilities (comfort and safety for passengers) at any driving situation. Recently, the Linear Parameter-Varying (LPV) control theory has been extended to fault tolerant control (FTC) systems to maintain the desired control goals as much as possible when a damper fault occurs. A scheduling parameter based on the load transfer is used to keep the equilibrium (comfort) when a semiactive damper fails in [31]; in [32], a supervisory system computes the compensation force that each healthy damper must add to reduce the fault effect, considering the semiactive constraints.
Recently, Tudón-Martínez [33] studied the effect of the oil leakage degree in the damping force using a commercial automotive shock absorber. Several degrees of oil leakage were implemented to analyze how the dynamic behavior of the MR damper is modified through the characteristic curves forcevelocity (FV) and force-displacement (FD). Figure 1 shows that the friction effect is reduced proportionally to the oil leakage degree; the linear stiffness also is reduced when the oil leakage increases; the nonlinearity in the viscous damping is modified and evidently the saturation force decreases inversely proportional to the damper leakage.

Experimental data of a Design of Experiments (DoE) with central composite design [34] illustrate that the damper leakage can be represented as a fault model of multiplicative nature [33]. By using an extension of a parametric model structure, for instance, the algebraic model of Guo et al. [13], a faulty MR damper can be modeled by a parameter identification algorithm as a static equation. In this model representation, the nominal parameters do not change; only the fault parameter modifies the force characteristics.

Because the parameter estimation approaches are sensitive to noise measurements and their online adaptation can require many computational resources, a robust estimation of the faulty force is essential. Indeed, the accuracy of the fault estimation not only determines the damper condition; this information can be used also to design Adaptive Vibration Control Systems to accommodate the lack of force caused by the faulty MR damper [32, 35-37].

Most of the work in Fault Detection and Isolation (FDI) modules for automobile suspensions is based on analytical redundancy, such as the parity space theory $[38,39]$, robust filtering [40], and nonlinear-robust observers [35, 36, 41]. The above approaches perform well for sensor faults or even for actuator faults considering active dampers that do not have any constraint on the force characteristics, in contrast to an MR damper whose semiactiveness, friction, and force saturation constraint the actuator properties.

An Adaptive Vibration Control System (AVCS) based on a robust LPV observer used to estimate faults in an MR damper is proposed in this paper. By using an $H_{\infty}$ design, the LPVAVCS system is robust to the road disturbances and noisy measurements. The LPV approach enables embedding the nonlinearities of the vehicle dynamics into varying parameters such that the observer becomes linearly parameter dependent with internal stability and robust performance. The inclusion of the faulty damper constraints as scheduling parameters into the $\mathrm{LPV} / \mathrm{H}_{\infty}$ observer makes the fault estimation fulfill the semiactiveness of the shock absorber in a practical implementation. The AVCS, based also on the LPV framework, uses the fault estimation to compute the needed compensation force in the healthy MR shock absorbers of the vehicle to reduce the effect of lack of force caused by the faulty damper (comfort deterioration).

The outline of this paper is as follows: in the next section, the problem statement is formulated. Section 3 details the design of the FDI system used to diagnose damper faults and Section 4 describes the AVCS. Section 5 illustrates the case study to validate the proposed FDI strategy under different tests and discusses the results in the AVCS. Concluding 


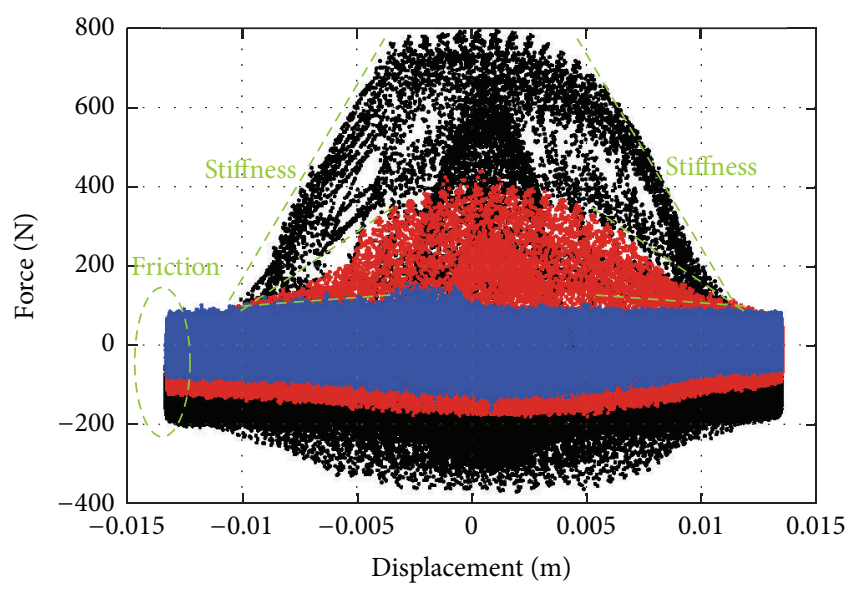

(a) FD characteristic curve

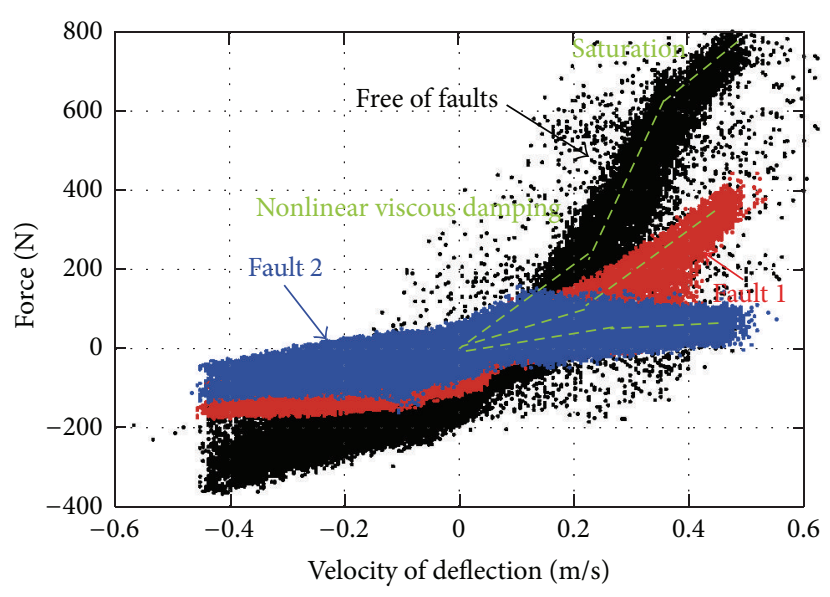

(b) FV characteristic curve

FIGURE 1: Experimental characteristic curves of a damper subject to leakages. Fault 1 represents 5\% of oil leakage and fault $210 \%$. The damper does not have control input value.

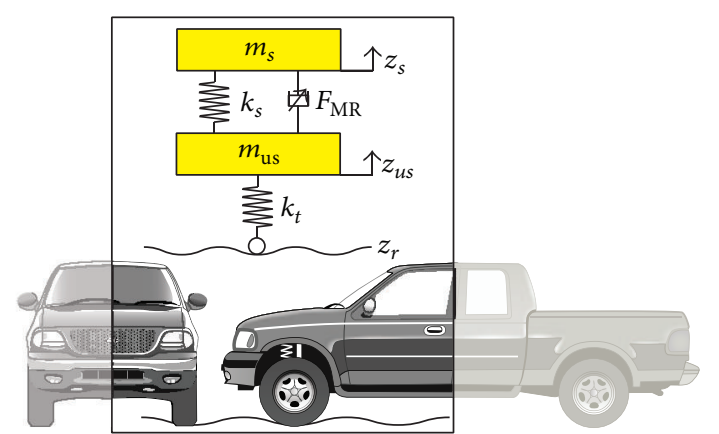

FIGURE 2: QoV model of an automotive semiactive suspension system.

remarks are presented in Section 6. The variables of this study are defined in the Abbreviations.

\section{Problem Statement}

The QoV model is the most basic system to represent an automotive suspension, Figure 2. Its use assumes an equivalent load distribution among the four corners and a linear dependency with respect to the translational and rotational chassis motions. The lateral and longitudinal wheel dynamics is not considered, while the wheel-road contact is ensured. The vertical dynamics of a QoV model is governed by

$$
\begin{aligned}
m_{s} \ddot{z}_{s}(t)= & -k_{s}\left[z_{s}(t)-z_{u s}(t)\right]-F_{\mathrm{MR}}(t), \\
m_{u s} \ddot{z}_{u s}(t)= & k_{s}\left[z_{s}(t)-z_{u s}(t)\right]-k_{t}\left[z_{u s}(t)-z_{r}(t)\right] \\
& +F_{\mathrm{MR}}(t) .
\end{aligned}
$$

The system considers a sprung mass $\left(m_{s}\right)$ and an unsprung mass $\left(m_{u s}\right)$. A spring with stiffness coefficient $k_{s}$ and an MR shock absorber represent the suspension between both masses. The spring is considered as linear because around $95 \%$ of its operating zone in an automotive application is linear; however, the MR damping force $\left(F_{\mathrm{MR}}\right)$ depends on a control input variable (electric current) and it is highly nonlinear with respect to the suspension motion. The stiffness coefficient $k_{t}$ models the wheel tire. The vertical position of the mass $m_{s}\left(m_{u s}\right)$ is defined by $z_{s}\left(z_{u s}\right)$, while $z_{r}$ corresponds to the unknown road disturbance. Because the MR damper represents the key element in the semiactive suspension control system, it is essential to model its nonlinearities and actuation properties with high accuracy to design model-based controllers, even more if the damper is faulty.

Consider an oil leakage on the MR damper in a QoV model, which induces a lack of force modeled as a multiplicative fault [33]; the faulty force expressed as a reduction of the nominal semiactive force $F_{\mathrm{MR}}$ is given by

$$
\bar{F}_{\mathrm{MR}}(t)=\alpha(t) F_{\mathrm{MR}}(t),
$$

where $\bar{F}_{\mathrm{MR}}$ is the reduced damping force and $\alpha \in(0,1]$ is the fault parameter associated with the oil leakage degree; for example, $\alpha=0.7$ means that the damping force will be of $70 \%$ of $F_{\mathrm{MR}}$ due to a lost force of $30 \%$. Thus, if $\alpha=1$, the semiactive damper is free of oil leakages. According to the nature of the oil leakage, the fault can be considered as abrupt (sudden leakage caused, e.g., by a seal worn out) or gradual (slow leakage caused, e.g., by wear).

To discriminate an operating change in the damping force (e.g., a change in the damper velocity, applied electric current, etc.) from a fault, a redundancy is needed (analytical or physical). In this paper the analytical redundancy consists in using a damper model and a nominal damper model, where both depend on the same variables except the fault. Another alternative is using redundant sensors (force, velocity, acceleration, pressure, etc.) to make the fault discrimination. 
Inspired on the parametric damper model of Guo et al. [13], which has good balance between performance and complexity, the damper fault in (2) can be represented by

$$
\begin{aligned}
\bar{F}_{\mathrm{MR}}(t) & =\alpha(t) \underbrace{\left[I(t) f_{c} \rho_{1}(t)+b_{1} \dot{z}_{\mathrm{def}}(t)+b_{2} z_{\mathrm{def}}(t)\right]}_{F_{\mathrm{MR}}(t)} \\
& =F_{\mathrm{MR}}(t)-F_{\delta}(t),
\end{aligned}
$$

where $I$ is the electric current to control the MR force and $\rho_{1}(t)=\tanh \left[a_{1} \dot{z}_{\text {def }}(t)+a_{2} z_{\text {def }}(t)\right] \in[0,1]$ represents the nonlinearities of the shock absorber. For $I=0, \bar{F}_{\mathrm{MR}}$ reduces to the passive damping force of the suspension system. $F_{\delta}$ is then interpreted as the lack of damping force from the nominal one, caused by the oil leakage.

By using the degree of leakage $\alpha$ in an MR damper as a varying parameter in the QoV model dynamics, which is estimable by physical features of the shock absorber (pressure sensors, accelerometers, etc.), an LPV observer can be used to estimate the faulty force $F_{\delta}$ instead of using a parameter estimation algorithm for (3) that is sensitive to noise measurements.

By substituting (3) into the vertical model dynamics of (1), a state-space representation of the QoV model with a damper leakage can be obtained as

$$
\underbrace{\left[\begin{array}{c}
\dot{z}_{s} \\
\ddot{z}_{s} \\
\dot{z}_{u s} \\
\ddot{z}_{u s}
\end{array}\right]}_{\dot{x}}=\underbrace{\left[\begin{array}{cccc}
0 & 1 & 0 & 0 \\
-\frac{h(\alpha)}{m_{s}} & -\frac{\alpha b_{1}}{m_{s}} & \frac{h(\alpha)}{m_{s}} & \frac{\alpha b_{1}}{m_{s}} \\
0 & 0 & 0 & 1 \\
\frac{h(\alpha)}{m_{u s}} & \frac{\alpha b_{1}}{m_{u s}} & -\frac{h(\alpha)+k_{t}}{m_{u s}} & -\frac{\alpha b_{1}}{m_{u s}}
\end{array}\right]}_{A} \underbrace{\left[\begin{array}{c}
z_{s} \\
\dot{z}_{s} \\
z_{u s}
\end{array}\right]}_{x}
$$$$
+\underbrace{\left[\begin{array}{cc}
0 & 0 \\
0 & \frac{-\alpha \cdot \rho_{1} f_{c}}{m_{s}} \\
0 & 0 \\
\frac{k_{t}}{m_{u s}} & \frac{\alpha \cdot \rho_{1} f_{c}}{m_{u s}}
\end{array}\right] \underbrace{\left[\begin{array}{c}
z_{r} \\
I
\end{array}\right]}_{u}}_{B}
$$

$$
\underbrace{\left[\begin{array}{c}
z_{\mathrm{def}} \\
\dot{z}_{\mathrm{def}}
\end{array}\right]}_{y}=\underbrace{\left[\begin{array}{cccc}
1 & 0 & -1 & 0 \\
0 & 1 & 0 & -1
\end{array}\right]}_{C}\left[\begin{array}{c}
z_{s} \\
\dot{z}_{s} \\
z_{u s} \\
\dot{z}_{u s}
\end{array}\right]
$$

with $h(\alpha)=k_{s}+\alpha b_{2}$.
By defining a generalized LPV plant $\Sigma(\theta)$ of the form of (5) using the faulty system matrices in (4), with $\theta:\left\{\alpha, \rho_{1}\right\}$, and augmented by the weighting function states as

$$
\begin{aligned}
\Sigma(\theta) & :=\left[\begin{array}{c}
\dot{\xi} \\
z_{\infty} \\
y
\end{array}\right] \\
& =\left[\begin{array}{c|ll}
\mathscr{A}(\theta) & \mathscr{B}_{1}(\theta) & \mathscr{B}_{2}(\theta) \\
\hline \mathscr{C}_{1}(\theta) & \mathscr{D}_{11}(\theta) & \mathscr{D}_{12}(\theta) \\
\mathscr{C}_{2}(\theta) & \mathscr{D}_{21}(\theta) & \mathscr{D}_{22}(\theta)
\end{array}\right]\left[\begin{array}{c}
\xi \\
w \\
u_{c}
\end{array}\right],
\end{aligned}
$$

it is possible to design an $\mathrm{LPV} / H_{\infty}$ observer of $F_{\delta}$ asymptotically stable in all variations of $\theta$, whose robust performance (estimation error) is defined as a control approach.

On considering that only one MR damper is faulty, the other three healthy MR dampers can be used for the fault compensation. Using the fault estimation (e.g., $F_{\delta_{1}}$ if the front-left MR damper is faulty), it is possible to determine the compensation forces $F_{c_{j}}, j=2,3,4$, from the vertical vehicle dynamics in the center of gravity of a 7-DOF model, such that

$$
\begin{aligned}
& m_{s_{c}} \ddot{z}_{s_{c}}=-\left(F_{k_{1}}+F_{\mathrm{MR}_{1}}-F_{\delta_{1}}+F_{k_{2}}+F_{\mathrm{MR}_{2}}+F_{c_{2}}+F_{k_{3}}\right. \\
& \left.\quad+F_{\mathrm{MR}_{3}}+F_{c_{3}}+F_{k_{4}}+F_{\mathrm{MR}_{4}}+F_{c_{4}}\right), \\
& I_{x x} \ddot{\theta}=\left(F_{k_{1}}+F_{\mathrm{MR}_{1}}-F_{\delta_{1}}-F_{k_{2}}-F_{\mathrm{MR}_{2}}-F_{c_{2}}\right) t_{f}+\left(F_{k_{3}}\right. \\
& \left.\quad+F_{\mathrm{MR}_{3}}+F_{c_{3}}-F_{k_{4}}-F_{\mathrm{MR}_{4}}-F_{c_{4}}\right) t_{r}, \\
& I_{y y} \ddot{\phi}=\left(F_{k_{4}}+F_{\mathrm{MR}_{4}}+F_{c_{4}}+F_{k_{3}}+F_{\mathrm{MR}_{3}}+F_{c_{3}}\right) l_{r}-\left(F_{k_{2}}\right. \\
& \left.\quad+F_{\mathrm{MR}_{2}}+F_{c_{2}}+F_{k_{1}}+F_{\mathrm{MR}_{1}}-F_{\delta_{1}}\right) l_{f},
\end{aligned}
$$

where $F_{k_{i}}=k_{s_{i}}\left(z_{s_{i}}-z_{u s_{i}}\right)$ are the stiffness forces of the springs and $F_{\mathrm{MR}_{i}}$, with $i=\in[1,4]$, are the nominal MR damping forces used in a free-fault case, and the compensation forces are specifically used to keep the balance in the vertical vehicle dynamics once a damper fails, such that

$$
\begin{array}{r}
F_{\delta_{1}}-F_{c_{2}}-F_{c_{3}}-F_{c_{4}}=0, \\
-t_{f} F_{\delta_{1}}-t_{f} F_{c_{2}}+t_{r} F_{c_{3}}-t_{r} F_{c_{4}}=0, \\
l_{r} F_{c_{4}}+l_{r} F_{c_{3}}-l_{f} F_{c_{2}}+l_{f} F_{\delta_{1}}=0 ;
\end{array}
$$

that is, the equilibrium only depends on the vehicle dimension parameters to make the load distribution.

The controlled force with fault adaptive features in a QoV is then composed by a nominal actuation $\left(I_{n}\left(F_{\mathrm{MR}}\right)\right.$, free-fault case) and by a compensation actuation $\left(I_{c}\left(F_{\delta}\right)\right.$, at presence of faults). Using an LPV controller, it is possible to design an AVCS that fulfills the semiactiveness and saturation constraints of the damper when the compensation force $F_{c_{j}}$ is added, such that the closed-loop system is

$$
\begin{aligned}
& \dot{x}=\mathscr{A}_{\mathrm{CL}}(\rho) \cdot x+\mathscr{B}_{1 \mathrm{CL}} \cdot \underbrace{\left(I_{n}+I_{c}\right)}_{K(\rho) \cdot x}+\mathscr{B}_{2 \mathrm{CL}} \cdot z_{r}, \\
& y=\mathscr{C}_{\mathrm{CL}}(\rho) \cdot x+\mathscr{D}_{1 \mathrm{CL}} \cdot\left(I_{n}+I_{c}\right)+\mathscr{D}_{2 \mathrm{CL}} \cdot z_{r}
\end{aligned}
$$


with $K(\rho)=\sum_{i=1}^{N} \xi_{i}(\rho) K_{i}$ by appropriately choosing the gains $K_{i}, i=1, \ldots, N$, such that the closed-loop system $\left(\mathscr{A}_{\mathrm{CL}}, \mathscr{B}_{1 \mathrm{CL}}, \mathscr{B}_{2 \mathrm{CL}}, \mathscr{C}_{\mathrm{CL}}, \mathscr{D}_{1 \mathrm{CL}}, \mathscr{D}_{2 \mathrm{CL}}\right)$ is asymptotically stable for all parameter variations. Two varying parameters are used in the controller design: $\rho_{1}^{*}$ represents the semiactiveness of the MR damper and $\rho_{2}^{*}$ its saturation that depends on the maximum damping force available for the compensation.

\section{LPV $/ H_{\infty}$ Fault Observer}

On using the bounded parameter $\alpha$, which represents a multiplicative damper fault in (2), it is possible to design an $\mathrm{LPV} / \mathrm{H}_{\infty}$ observer to determine the lack of force caused by the damper leakage.

3.1. LPV Modeling. From (4), an LPV model structure can be expressed as

$$
\begin{aligned}
& \dot{x}=A(\alpha) \cdot x+B\left(\alpha, \rho_{1}\right) \cdot u, \\
& y=C \cdot x .
\end{aligned}
$$

However, the model of (9) does not respect the polytopic solution because the system is parameter dependent on the input. In order to make $B$ parameter independent and get a proper structure for the LPV based controller synthesis [22], the model in (9) is a state-augmented system by adding a lowpass filter $W_{\text {filter }}=\omega_{f} /\left(s+\omega_{f}\right)$ with state $x_{f}$ and matrices $\left(A_{f}\right.$, $B_{f}, C_{f}$ ), such that the new LPV model is given by

$$
\begin{aligned}
\underbrace{\left[\begin{array}{c}
\dot{x} \\
\dot{x}_{f}
\end{array}\right]}_{\dot{x}_{p}} & \underbrace{\left[\begin{array}{cc}
A(\alpha) & B_{1}\left(\alpha, \rho_{1}\right) C_{f} \\
0_{1 \times 4} & A_{f}
\end{array}\right]}_{A_{p}\left(\alpha, \rho_{1}\right)} \underbrace{\left[\begin{array}{c}
x \\
x_{f}
\end{array}\right]}_{x_{p}}+\underbrace{\left[\begin{array}{c}
B_{2} \\
0
\end{array}\right]}_{B_{p 1}} z_{r} \\
& +\underbrace{\left[\begin{array}{c}
0_{4 \times 1} \\
B_{f}
\end{array}\right] I,}_{B_{p 2}} \\
y= & \underbrace{\left[\begin{array}{ll}
C & 0_{2 \times 1}
\end{array}\right]}_{C_{p}}\left[\begin{array}{c}
x \\
x_{f}
\end{array}\right],
\end{aligned}
$$

where $B_{1}$ is the column matrix of $B$ associated with $I$ and $B_{2}$ is the column matrix of $B$ associated with the road profile $z_{r}$ in (4).

Scheduling Parameters. The LPV system in (10) includes 2 time-varying parameters, assuming that both can be estimated directly from measurements or by additional sensors. The formed polytope represents a quadrilateral polygon, whose vertices are given by the bounded values of $\rho_{1} \in[-1,1]$ and $\alpha \in(0,1]$.

By defining the set of four Linear Time-Invariant (LTI) systems, the main idea is to design an LPV observer of the missing force caused by the damper leakage, whose convex combination is stable for all trajectories of the varying parameters by solving an LMI problem.
3.2. $L P V / H_{\infty}$ Observer Design. Based on the LPV model of (10), an $\mathrm{LPV} / H_{\infty}$ observer is designed to estimate the damping force lost by the oil leakage in the shock absorber, adding robustness to unknown road disturbances. The frequency specification performance is to reduce the estimation error of the faulty force $\left(e=F_{\delta_{\text {model }}}-\widehat{F}_{\delta}(y)\right) ; W_{e}$ represents the weighting function used to minimize the estimation error in the frequency range of interest for the suspension motion, while $W_{z r}$ shapes the road irregularities in the observer design in a frequency band of interest, even narrow-banded:

$$
W_{r}=\frac{K_{r} \omega_{r} s}{s+\omega_{r}}
$$

to add robustness to road disturbances,

$$
W_{e}=\frac{K_{e}\left(s^{2}+2 \zeta_{e_{1}} \omega_{e_{1}} s+\omega_{e_{1}}^{2}\right)}{s^{2}+2 \zeta_{e_{2}} \omega_{e_{2}} s+\omega_{e_{2}}^{2}}
$$

to add robustness to noisy measurements.

By considering the filtering specifications, the generalized plant $\Sigma\left(\alpha, \rho_{1}\right)$ used for the synthesis of the $H_{\infty}$ observer is given by (13). Figure 3 shows the structure of its design:

$$
\begin{aligned}
\Sigma\left(\alpha, \rho_{1}\right) & :=\left[\begin{array}{c}
\dot{\xi} \\
\hline z_{\infty} \\
y
\end{array}\right] \\
& =\left[\begin{array}{c|ccc}
\mathscr{A}\left(\alpha, \rho_{1}\right) & \mathscr{B}_{1} & \mathscr{B}_{2} & \mathbf{0} \\
\hline \mathscr{C}_{\infty}\left(\alpha, \rho_{1}\right) & \mathbf{0} & \mathbf{0} & \mathscr{D}_{\infty} \\
\mathscr{C} & \mathbf{0} & \mathscr{C}_{I} & \mathbf{0}
\end{array}\right]\left[\begin{array}{c}
\xi \\
w \\
I \\
u_{c}
\end{array}\right]
\end{aligned}
$$

with

$$
\begin{aligned}
\mathscr{A}\left(\alpha, \rho_{1}\right) & =\left[\begin{array}{cc}
A_{p}\left(\alpha, \rho_{1}\right) & \mathbf{0} \\
\mathbf{0} & A_{w}
\end{array}\right], \\
\mathscr{B}_{1} & =\left[\begin{array}{c}
B_{p 1} W_{r} \\
\mathbf{0}
\end{array}\right], \\
\mathscr{B}_{2} & =\left[\begin{array}{c}
B_{p 2} \\
\mathbf{0}
\end{array}\right], \\
\mathscr{C} & =\left[\begin{array}{cc}
C_{p} & \mathbf{0} \\
\mathbf{0} & \mathbf{0}
\end{array}\right], \\
\mathscr{C}_{I} & =\left[\begin{array}{l}
\mathbf{0} \\
1
\end{array}\right],
\end{aligned}
$$

where $\xi=\left[\begin{array}{ll}x_{p} & x_{w}\end{array}\right]^{T}$ such that $x_{p}$ are the states in the vertical dynamics of the augmented QoV model of (10) and $x_{w}$ are the vertical weighting functions states, $\mathscr{C}_{\infty}\left(\alpha, \rho_{1}\right)$ and $\mathscr{D}_{\infty}$ represent the controlled output $z_{\infty}$ with frequency specifications in $W_{e}$ to minimize the estimation error $e(t)$ in the frequency band of interest, $y=\left[\begin{array}{lll}z_{\text {def }} & \dot{z}_{\text {def }} I\end{array}\right]^{T}$ is 


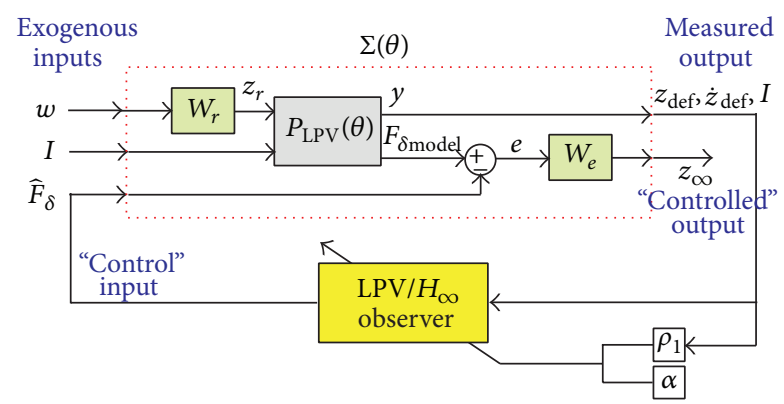

FIGURE 3: LPV/ $H_{\infty}$ observer design in a QoV model to estimate the faulty force caused by a damper leakage (inspired as a control approach).

the measured output, $w$ is the unknown disturbance, $I$ is the electric current (manual actuation in open-loop), and $u_{c}=$ $u^{H_{\infty}}$ is the observer output, in this case the estimated faulty force $\widehat{F}_{\delta}$ which is considered as control input into the observer design, Figure 3.

The $\mathrm{LPV} / \mathrm{H}_{\infty}$ observer is given by

$$
\left[\begin{array}{c}
\dot{x}_{o}(t) \\
\widehat{F}_{\delta}(t)
\end{array}\right]=\left[\begin{array}{ll}
A_{o}(\theta(t)) & B_{o}(\theta(t)) \\
C_{o}(\theta(t)) & D_{o}(\theta(t))
\end{array}\right]\left[\begin{array}{c}
x_{o}(t) \\
y(t)
\end{array}\right]
$$

and is quadratically stable by solving an optimization problem with LMI techniques [42]. The observer reduces the effect of the road disturbances and avoids drifting in the estimation of the missed force by decreasing asymptomatically the error dynamics.

Remark 1. Let $\Sigma\left(\theta_{1}, \ldots, \theta_{r}\right)$ be the generalized plant of an LPV faulty model with matrices $\mathscr{A}\left(\theta_{1}, \ldots, \theta_{r}\right), \mathscr{B}_{i}, \mathscr{C}_{j}$, and $\mathscr{D}_{i j}$ as in (13), where the input matrices are parameter independent as well as the output matrices; then it is possible to build a set of LMIs by applying the Bounded Real Lemma. To reduce the optimization problem into a finite number of LMIs, the solution is reached at each vertex of the polytope given by (16), by ensuring quadratic and robust stability in the closedloop system $[42,43]$ :

$$
\begin{aligned}
& \Sigma(\theta):\left[\begin{array}{l|l}
A(\theta) & B(\theta) \\
\hline C(\theta) & D(\theta)
\end{array}\right] \\
& =\sum_{i=1}^{N} \delta_{i}(\theta)\left[\begin{array}{l|l}
A\left(\omega_{i}\right) & B\left(\omega_{i}\right) \\
\hline C\left(\omega_{i}\right) & D\left(\omega_{i}\right)
\end{array}\right] \\
& \in \operatorname{Co}\left\{\left[\begin{array}{c|c}
A_{1} & B_{1} \\
\hline C_{1} & D_{1}
\end{array}\right], \ldots,\left[\begin{array}{c|c}
A_{N} & B_{N} \\
\hline C_{N} & D_{N}
\end{array}\right]\right\},
\end{aligned}
$$

where $\omega_{i}$ are the $2^{r}$ vertices of the polytope given by all combinations of the limit values of the varying parameters and $\delta_{i}(\theta)$ is the weighting parameter among the LTI systems, defined by

$$
\begin{aligned}
\delta_{i}(\theta): \frac{\prod_{j=1}^{r}\left|\theta_{j}-\mathscr{C}\left(\omega_{i}\right)_{j}\right|}{\prod_{j=1}^{r}\left(\overline{\theta_{j}}-\underline{\theta_{j}}\right)}, \\
\quad i=1, \ldots, N \text { where } \delta_{i}(\theta)>0, \sum_{i=1}^{N} \delta_{i}(\theta)=1,
\end{aligned}
$$

where $\mathscr{C}\left(\omega_{i}\right)_{j}$ is the $j$ th component of the vector $\mathscr{C}\left(\omega_{i}\right)$ given by

$$
\mathscr{C}\left(\omega_{i}\right)_{j}: \begin{cases}\theta_{j}=\overline{\theta_{j}} & \text { if }\left(\omega_{i}\right)_{j}=\underline{\theta_{j}} \\ \theta_{j}=\underline{\theta_{j}} & \text { otherwise. }\end{cases}
$$

By defining the performance criterion as the minimization of the estimation error of the faulty force $\left(e=F_{\delta_{\text {model }}}-\right.$ $\left.\widehat{F}_{\delta}(y)\right)$ in terms of an $H_{\infty}$ problem, the global LPV/ $H_{\infty}$ observer will be the convex combination of $2^{r}$ local observers of the form of (19) by solving the set of LMI problems, whose solution is the extended result from the LTI systems, proposed by [42]

$$
L(\theta):\left[\begin{array}{c}
\dot{x}_{o} \\
\widehat{F}_{\delta}
\end{array}\right]=\left[\begin{array}{cc}
A_{o}(\theta) & B_{o}(\theta) \\
C_{o}(\theta) & D_{o}(\theta)
\end{array}\right]\left[\begin{array}{c}
x_{o} \\
y
\end{array}\right] .
$$

\section{Adaptive Vibration Control System}

Once a damper leakage affects the vehicle suspension, the first step is to determine as soon as possible which corner has suffered the lack of force. Afterwards, this fault must be estimated to compute the required compensation force in the healthy dampers.

By using an $\mathrm{LPV} / \mathrm{H}_{\infty}$ observer at each vehicle corner, it is possible to monitor online the behavior of the four MR dampers. If there are no faults on the dampers, $F_{\delta_{i}} \sim 0$, and consequently all compensations forces $F_{c_{j}} \sim 0$ for $i \neq j$. However, when a fault occurs in one MR damper, the fault isolation, detection, and estimation are naturally possible because the four LPV observers are decoupled thanks to the vehicle dynamics.

Since $F_{\delta_{i}}$ is not measured but estimated from an LPV observer using (19), this allows the straightforward computation of the compensation forces $F_{c_{j, j \neq i}}$ according to (7a), (7b), and (7c), such that the full matrix of compensation obtained by the equilibrium of the load distribution when one MR damper fails is given by

$$
\left[\begin{array}{l}
F_{c_{1}} \\
F_{c_{2}} \\
F_{c_{3}} \\
F_{c_{4}}
\end{array}\right]=\left[\begin{array}{cccc}
0 & 1 & \frac{t_{r}}{t_{f}} & -\frac{t_{r}}{t_{f}} \\
1 & 0 & -\frac{t_{r}}{t_{f}} & \frac{t_{r}}{t_{f}} \\
\frac{t_{f}}{t_{r}} & -\frac{t_{f}}{t_{r}} & 0 & 1 \\
-\frac{t_{f}}{t_{r}} & \frac{t_{f}}{t_{r}} & 1 & 0
\end{array}\right]\left[\begin{array}{c}
\widehat{F}_{\delta_{1}} \\
\widehat{F}_{\delta_{2}} \\
\widehat{F}_{\delta_{3}} \\
\widehat{F}_{\delta_{4}}
\end{array}\right] .
$$




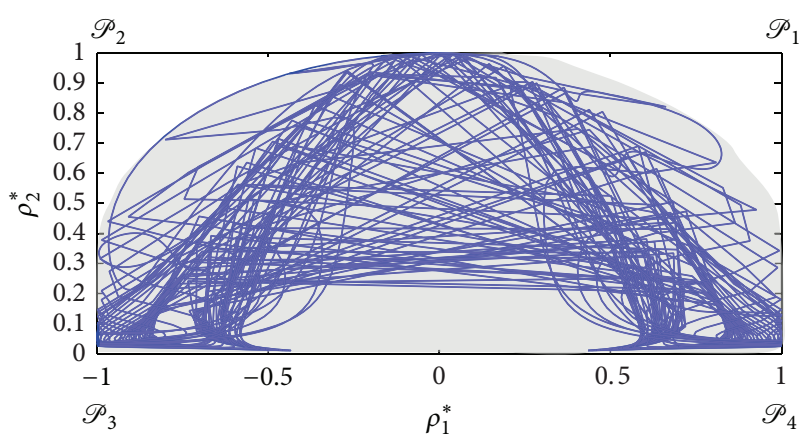

FIGURE 4: Operating region of the scheduling parameters $\rho_{1}^{*}$ and $\rho_{2}^{*}$.

For multiple faults, that is, faults in two or three dampers of the vehicle, two aspects must be considered:

(1) The equilibrium of the load transfer in the chassis, including the simultaneous faults, must be guaranteed using the compensation force matrix of (20).

(2) Mechanically, the MR damper must be designed with enough damping force (plus the nominal force used in the fault-free case) in order to have faculty to accommodate the lack of damping force of two or more faulty actuators.

4.1. Fault Tolerant Control Based on LPV. The control of the vertical dynamics, adaptive to the damper fault, can be ensured by the LPV control theory to achieve frequency specification performances [44]. Based on [45] that embeds into the control design the constraints of dissipativity and saturation of a semiactive damper with two scheduling parameters, here an $\mathrm{LPV} / H_{\infty}$ controller is designed at each corner for (a) compensation of lack of damping force of a faulty damper (fault accommodation) and (b) performances of comfort and road holding against road disturbances and uncertainties when a damper leakage occurs.

Scheduling Parameters. Two varying parameters are used in the LPV controller synthesis for each corner: $\rho_{1}^{*}$ includes the nonlinearities of the damper and is given by

$$
\begin{aligned}
\rho_{1}^{*} & =\tanh \left(a_{1} \dot{z}_{\mathrm{def}}+a_{2} z_{\mathrm{def}}\right) \cdot \frac{\tanh \left(I_{f} /\left(I_{n 0}+I_{c 0}\right)\right)}{I_{f} /\left(I_{n 0}+I_{c 0}\right)} \\
& \in[-1,1]
\end{aligned}
$$

where $I_{n 0}$ and $I_{c 0}$ are the average of electric currents dedicated for the nominal suspension control and compensation. $I_{f}=$ $I_{n}+I_{c}$ is the electric current (controller output) bounded by the saturation constraint:

$$
0 \leq I_{\min }<I_{f} \leq I_{\max }
$$

$\rho_{2}^{*}$ is used directly to saturate the controller output, given by

$$
\rho_{2}^{*}=\frac{\tanh \left(a_{1} \dot{z}_{\mathrm{def}}+a_{2} z_{\mathrm{def}}\right)}{a_{1} \dot{z}_{\mathrm{def}}+a_{2} z_{\mathrm{def}}} \cdot\left(I_{n o}+I_{c o}\right) \in\left[0, \frac{I_{\mathrm{max}}}{2}\right] .
$$

Figure 4 shows the operating region for both scheduling parameters when the QoV model of one corner is subject to a chirp road signal with enough frequency content. The operating region of the polytope is similar to a half ellipsoid; note that there are some areas where the varying parameters are not contained (close to the polytopes $\mathscr{P}_{1}$ and $\mathscr{P}_{2}$ ), which could be used to reduce the conservatism.

Because the polytopic LPV controller is defined by the scheduling parameters, whose limit values are associated with the minimum and maximum damping force, the transient response of the damper in an online operation is inside of the polytope region such that the response speed of the MR fluid does not affect the frequency specification performances in the controller.

Note that there is a compromise between the control performances and the compensation because $I_{n 0}+I_{c 0}=$ $I_{\max } / 2$; the capability to compensate for a faulty damper is limited by

$$
I_{c}= \begin{cases}I_{c}=2 \cdot I_{c 0} & \text { if } I\left(F_{c}\right) \geq I_{c_{\max }} \\ 0<I_{c}<2 \cdot I_{c 0} & \text { if } I_{c_{\min }}<I\left(F_{c}\right)<I_{c_{\max }} \\ I_{c}=0 & \text { if } I\left(F_{c}\right)<I_{c_{\min }},\end{cases}
$$

where $I\left(F_{c}\right)=\left[F_{c} \cdot \operatorname{coth}\left(a_{1} \dot{z}_{\text {def }}+a_{2} z_{\text {def }}\right)\right] / f_{c}$ is the inverse dynamics of the MR damper model, (3) with $\alpha=1$, which depends on the compensation force, (20), and $I_{c_{\max }}=2 \cdot I_{c 0}$ is the maximum electric current available for compensation. If the faulty damper requires a greater force than the one that could be generated by $I_{c_{\max }}$, the fault will not be well accommodated. In the fault-free case, $I_{c}=0$, and the nominal suspension controller works inside the saturation constraint $\left[I_{n_{\min }}, I_{n_{\max }}\right]$. Figure 5 shows a scheme to represent the electric current used for the compensation and its interaction with the nominal control actuation.

LPV Modeling Formulation. Following [45], an LPV controller for each healthy MR damper is designed to accommodate the fault of other dampers. The LPV controller is able to handle the nonlinearity of the semiactive damper model and the saturation constraint (represented by the maximum limit of the input electric current $I_{f}$ ). The considered LPV model in this study also is a state-augmented system by adding a low-pass filter to get a proper structure for the LPV controller synthesis [22]. The new LPV QoV model is given by

$$
\begin{aligned}
& \underbrace{\left[\begin{array}{c}
\dot{x} \\
\dot{x}_{f}
\end{array}\right]}_{\dot{x}_{s}}=\underbrace{\left[\begin{array}{cc}
A+\rho_{2}^{*} B_{I 0} C_{I 0} & B_{1}\left(\rho_{1}^{*}\right) C_{f} \\
0_{1 \times 4} & A_{f}
\end{array}\right]}_{A_{s}\left(\rho_{1}^{*}, \rho_{2}^{*}\right)} \underbrace{\left[\begin{array}{c}
x \\
x_{f}
\end{array}\right]}_{x_{s}} \\
& +\underbrace{\left[\begin{array}{c}
B_{2} \\
0
\end{array}\right]}_{B_{s 1}} z_{r}+\underbrace{\left[\begin{array}{c}
0_{4 \times 1} \\
B_{f}
\end{array}\right]}_{B_{s 2}} u_{c} \text {, } \\
& y=\underbrace{\left[\begin{array}{ll}
C & 0_{2 \times 1}
\end{array}\right]}_{C_{s}}\left[\begin{array}{c}
x \\
x_{f}
\end{array}\right]
\end{aligned}
$$




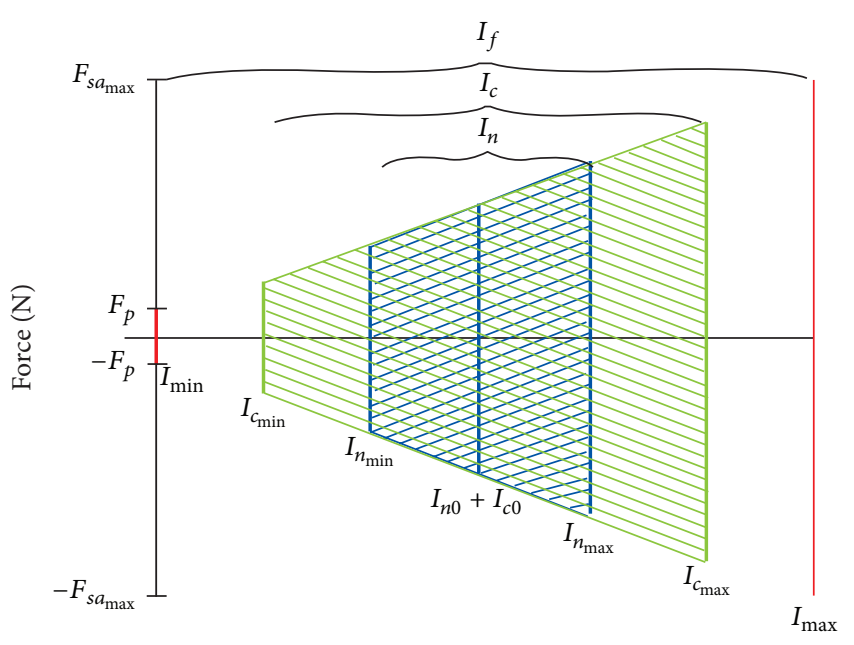

Electric current (A)

FIGURE 5: Force-electric current diagram in a healthy MR damper used for the adaptive control.

with

$$
\begin{aligned}
B_{I 0} & =\left[\begin{array}{llll}
-\frac{I_{n 0}+I_{c 0}}{m_{s}} & 0 & \frac{I_{n 0}+I_{c 0}}{m_{s}} & 0
\end{array}\right]^{T}, \\
C_{I 0} & =\left[\begin{array}{llll}
a_{1} & a_{2}-a_{1} & -a_{2}
\end{array}\right],
\end{aligned}
$$

where $B_{1}$ is the column matrix of $B$ associated with $I$ and $B_{2}$ is the column matrix of $B$ associated with the road profile $z_{r}$ in (4). Note that the matrix $A$ does not depend on $\alpha$ because the compensation purpose is based on healthy dampers.

$L P V / H_{\infty}$ Control Design. The extension to the method in [45] lies into the parameter $\rho_{2}^{*}$ that incorporates the damping force used to compensate the faulty damper. The control design satisfies the actuator constraints. Indeed, depending on the value of the fault, the semiactive suspension is adapted to meet the required robust performances in comfort and road holding, according to the following frequency specifications:

$$
\begin{aligned}
W_{r} & =\frac{K_{r} \omega_{r} s}{s+\omega_{r}} \text { to add robustness to road disturbances, } \\
W_{\ddot{z}_{s}} & =\frac{K_{s}\left(s^{2}+2 \zeta_{1 s} \omega_{1 s} s+\omega_{1 s}^{2}\right)}{s^{2}+2 \zeta_{2 s} \omega_{2 s} s+\omega_{2 s}^{2}}
\end{aligned}
$$

to reduce the vertical acceleration of $m_{s}$ in its natural frequency,

$W_{z_{u s}}=\frac{K_{u s}\left(s^{2}+2 \zeta_{1 u s} \omega_{1 u s} s+\omega_{1 u s}^{2}\right)}{s^{2}+2 \zeta_{2 u s} \omega_{2 u s} s+\omega_{2 u s}^{2}}$

to reduce the vertical displacement of $m_{u s}$ at high frequencies,

where $W_{\ddot{z}_{s}}$ is a high-pass filter with cut-off frequency greater than the natural frequency of the sprung mass, $W_{z_{u s}}$ is a low-pass filter with cut-off frequency lower than the natural frequency of the unsprung mass, and $W_{r}$ can be a first-order filter to shape the road disturbances or a band pass filter to increase the sensitivity in a frequency band of interest.
Taking into account the control specifications, the generalized system $\Sigma\left(\rho_{1}^{*}, \rho_{2}^{*}\right)$ used for the LPV control synthesis is given by

$$
\begin{aligned}
\Sigma\left(\rho_{1}^{*}, \rho_{2}^{*}\right) & :=\left[\begin{array}{c}
\dot{\xi} \\
\hline z_{\infty} \\
y
\end{array}\right] \\
& =\left[\begin{array}{c|cc}
\mathscr{A}\left(\rho_{1}^{*}, \rho_{2}^{*}\right) & \mathscr{B}_{1} & \mathscr{B}_{2} \\
\hline \mathscr{C}_{\infty} & \mathbf{0} & \mathbf{0} \\
\mathscr{C} & \mathbf{0} & \mathbf{0}
\end{array}\right]\left[\begin{array}{c}
\xi \\
\hline w \\
u_{c}
\end{array}\right]
\end{aligned}
$$

with

$$
\begin{aligned}
\mathscr{A}\left(\rho_{1}^{*}, \rho_{2}^{*}\right) & =\left[\begin{array}{cc}
A_{s}\left(\rho_{1}^{*}, \rho_{2}^{*}\right) & \mathbf{0} \\
\mathbf{0} & A_{w}
\end{array}\right], \\
\mathscr{B}_{1} & =\left[\begin{array}{c}
B_{s 1} W_{z_{r}} \\
\mathbf{0}
\end{array}\right], \\
\mathscr{B}_{2} & =\left[\begin{array}{c}
B_{s 2} \\
\mathbf{0}
\end{array}\right], \\
\mathscr{C} & =\left[\begin{array}{ll}
C & \mathbf{0}
\end{array}\right],
\end{aligned}
$$

where $\xi=\left[\begin{array}{ll}x_{s} & x_{w}\end{array}\right]^{T}$ such that $x_{s}$ are the states in the vertical dynamics of the augmented QoV model of (25) and $x_{w}$ are the vertical weighting functions states with dynamics $A_{w}$, $z_{\infty}=\left[\begin{array}{ll}z_{1} & z_{2}\end{array}\right]^{T}$ is the controlled output with dynamics $\mathscr{C}_{\infty}$, $y=\left[\begin{array}{ll}z_{\mathrm{def}} & \dot{z}_{\mathrm{def}}\end{array}\right]^{T}$ is the measured output with dynamics $C$ that represents the state feedback, and $u_{c}=u^{H_{\infty}}$ is the controller output.

Problem Solution. The $\mathrm{LPV} / \mathrm{H}_{\infty}$ controller is synthesized in the LMI framework for polytopic systems according to [42]; all varying parameters are bounded in $\rho_{1}^{*} \in[-1,1]$ and $\rho_{2}^{*} \in\left[0, I_{\max } / 2\right]$ with $I_{\max }=6 \mathrm{~A}$. The resulting global $\mathrm{LPV} / \mathrm{H}_{\infty}$ controller is a convex combination of the local controllers obtained by solving the set of LMIs only on each vertex of the polytope formed by the limit values of the varying parameters. Since 2 varying parameters are used, each QoV considers a polytope of 4 vertices; that is, 4 local LTI controllers are obtained, such that

$$
\begin{aligned}
& K(\rho):\left[\begin{array}{ll}
A_{c}(\rho) & B_{c}(\rho) \\
C_{c}(\rho) & D_{c}(\rho)
\end{array}\right] \\
& =\sum_{i=1}^{2^{2}} \xi_{i}(\rho) K_{i}=\sum_{i=1}^{2^{2}} \xi_{i}(\rho)\left[\begin{array}{ll}
A_{c_{i}} & B_{c_{i}} \\
C_{c_{i}} & D_{c_{i}}
\end{array}\right] .
\end{aligned}
$$

The controller stability is guaranteed for all trajectories of the varying parameters, even if an extra compensation force is demanded, by solving the LMI problem at each vertex expressed by the Bounded Real Lemma $[42,46]$ as

$$
\left[\begin{array}{ccc}
\mathscr{A}(\rho)^{T} K(\rho)+K(\rho) \mathscr{A}(\rho) & K(\rho) \mathscr{B} & \mathscr{C}_{\infty}^{T} \\
\mathscr{B}^{T} K(\rho) & -\gamma_{\infty}^{2} I & \mathbf{0} \\
\mathscr{C}_{\infty} & \mathbf{0} & -I
\end{array}\right]<0 .
$$




\section{Simulation Results}

The evaluation of the proposed AVCS for MR damper faults has been separated into two sections: (a) firstly, the performance of the fault observer is analyzed using different simulation tests, and then it is compared with respect to a parameter estimation method considering noise on the measurements; (b) secondly, the fault tolerant controller is evaluated when one damper fails and the other three MR dampers are used for the fault compensation.

5.1. Estimation of MR Damper Faults. To evaluate the performance of the LPV/ $H_{\infty}$ observer, the front-left corner of a medium payload pickup truck has been used as test-bed, Figure 2, whose experimental parameters obtained by a test of kinematics and compliance are $m_{s}=630 \mathrm{Kg}, m_{u s}=81.5 \mathrm{Kg}$, $k_{s}=43,500 \mathrm{~N} / \mathrm{m}$, and $k_{t}=230,000 \mathrm{~N} / \mathrm{m}$.

Experimental data obtained from a commercial MR damper are used to model the nonlinearities of this actuator by considering $\alpha=1$ in (3), according to the methodology of characterization of MR dampers in [34]. De-J Lozoya-Santos et al. [34] present a discussion about the required experimentation to characterize MR dampers exclusively to describe the physical phenomena, or according to a target application (control design purposes, study of the vehicle dynamics, mechanical configuration, etc.). In this study, the used experiments were chosen to describe the different physical MR phenomena of the shock absorber (stiffness, nonlinear viscous damping, friction, and saturation) in the full range of frequencies of interest with common rod displacements in a car. The Design of Experiments (DoE) used to characterize the hysteresis loops and nonlinear transient response of the MR damping force includes different sequences of displacement (suspension deflection) and electric current (manipulation variable) in a composite design.

The commercial MR damper used to perform different experimental tests of identification was manufactured by Delphi MagneRide for SUVs. The range of force is $\pm 8,000 \mathrm{~N}$ (peak to peak); the stroke is around $40 \mathrm{~mm}$ with a time constant of $14 \mathrm{~ms}$ and settling time of $84 \mathrm{~ms}$. This shock absorber has continuous actuation (from 0 to $6 \mathrm{~A}$ ) and considerable hysteresis at high frequencies with high deflections. Figure 6(a) shows the FV curve of the MR damper using an experiment with excitation of displacement up to $15 \mathrm{~Hz}$ at different $I$ values; note that the yield stress of the MR fluid reaches the saturation of $8,000 \mathrm{~N}$ when $I=6 \mathrm{~A}$ and the frequency of motion is $15 \mathrm{~Hz}$.

Figure 6(b) shows the performance of the MR damper model used in the simulations, (3), whose parameters were obtained from a standard ISO road profile type D: $f_{c}=600.9$, $a_{1}=37.8, a_{2}=22.1, b_{1}=2,830.8$, and $b_{2}=-7,897.2$.

In the simulation tests to evaluate the FDI module based on the LPV observer, the road profile is composed of a chirp signal from 0 to $8 \mathrm{~Hz}$. Gaussian noise is assumed in the $z_{\text {def }}$ and $\dot{z}_{\text {def }}$ measurements. Two fault scenarios have been studied:

(i) An abrupt damper leakage from $t=5$ to $10 \mathrm{~s}$ with $20 \%$ of lack of force $(\alpha=0.8)$ and from $t=13$ to $18 \mathrm{~s}$

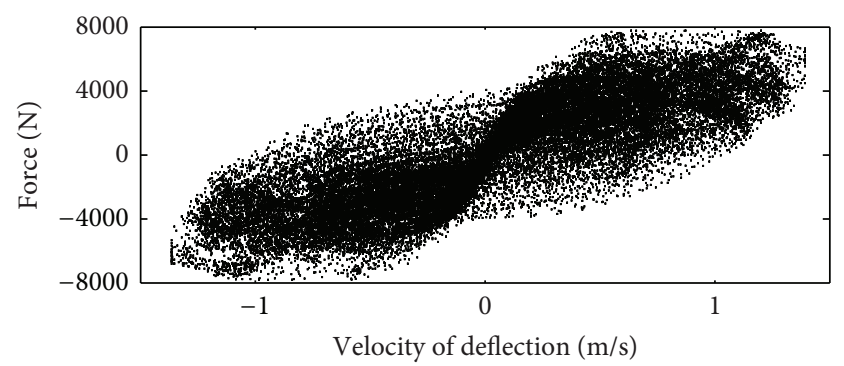

(a) Experimental damping force

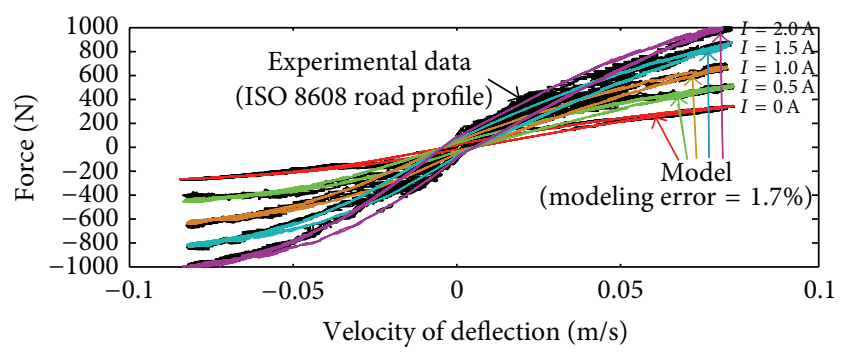

(b) MR damper model performance

FIgURE 6: (a) Experimental data of the commercial MR damper when the damper rod is excited by a chirp signal from 0.5 to $15 \mathrm{~Hz}$ at different stepped values of electric current from 0 to 6 A. (b) MR damper modeling for different $I$ values, when $\alpha=1$.

with $50 \%$ of lack of force $(\alpha=0.5)$ : during whole test, the electric current on the MR damper is constant, $I=1 \mathrm{~A}$. This test studies the property of the LPV observer to schedule the fault estimation according to the $\alpha$ value.

(ii) A gradual damper leakage from $0 \%$ of lack of force $(\alpha=1)$ at $t=5 \mathrm{~s}$ until $50 \%$ of lack of force $(\alpha=0.5)$ at $t=20 \mathrm{~s}$ : in this test, the electric current is a random signal from 0 to $2.5 \mathrm{~A}$ that mimics a controller output on the MR damper. This test studies the transient response of the fault estimation and its insensitivity to the manipulation variable.

The robust fault estimation of the LPV observer was compared with respect to a static fault estimation using (3), which depends on the reliability of the model parameters and it can be affected by the noise in the measurements of $z_{\text {def }}$ and $\dot{z}_{\text {def }}$.

Figure 7 shows the performance of the $\mathrm{LPV} / \mathrm{H}_{\infty}$ observer in both tests. Note that the transient response of the fault estimation with the LPV observer is robust to the noise of measurements; however, the static estimation is noisy at all frequencies even when the damper is free of faults. Indeed, the fault estimation with the static equation has more amplitude than the correct one, as the frequency increases.

Because the transient response of the LPV observer represents correctly the implemented fault in both tests, the proposed observer can estimate abrupt or gradual damper leakages of any magnitude for all trajectories bounded by $\alpha$ that belong to a convex LMI solution. Also, Figure 7 illustrates that the $\mathrm{LPV} / \mathrm{H}_{\infty}$ observer is robust to road 


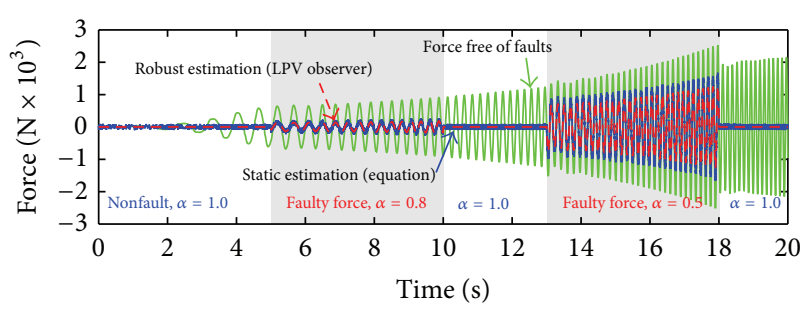

(a) Test with abrupt damper leakages

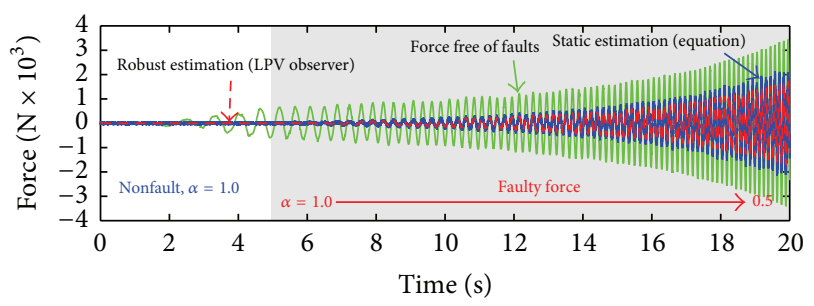

(b) Test with a gradual damper leakage

FIGURE 7: Fault estimation performance with the $\mathrm{LPV} / \mathrm{H}_{\infty}$ observer.

disturbances (road profile at different sinusoidal frequencies and amplitudes), and the fault estimation is insensitive to the value of electric current on the MR damper; that is, a closedloop implementation does not affect the FDI performance. Indeed, $I$ is only a gain in the semiactive force, such that

$$
F_{\delta}=F_{\mathrm{MR}}(I)-\alpha F_{\mathrm{MR}}(I),
$$

where both terms in right side are dependent on $I$ and its difference has only dependence on $\alpha$.

A correct estimation of $F_{\delta}$ in the FDI module avoids unrealistic control reconfigurations or fault accommodations for fault tolerant control purposes. For instance, the static estimation of the fault in Figure 7 overshoots around $800 \mathrm{~N}$ from the real fault in some frequencies; this incorrect fault information will demand more damping force of compensation than the required one by the actuator or by external actuators (other healthy dampers in the vehicle) to reduce the fault effect.

5.2. Control Adaptation for MR Damper Faults. When an oil leakage occurs in one of the dampers and the car is moving, the lack of damping force increases the vertical vehicle body motion. To reduce the fault propagation into the vertical dynamics, the obtained FDI information is used by the AVCS to compensate for the faulty damper and thus maintain the comfort in the vehicle.

Figure 8 schematizes the proposed AVCS, in particular the interaction between the FDI module and the LPV controller. Once a damper leakage is detected and estimated, the load distribution analysis determines the compensation force that the healthy dampers must deliver. Finally, at each corner, the LPV based controller is adapted to accommodate the fault through $F_{c_{i}}$, fulfilling the MR damper constraints (semiactiveness and saturation).

A vehicle CarSim model was used to evaluate the proposed AVCS; the suspension model was characterized from real data curves (camber angles, caster angles, damping force, jounce/rebound stops, spring, tire stiffness, etc.), structural parameters (mechanical ratios, compliance coefficients, Kingpin geometry, etc.), and physical dimensions (weight, length, width, height, wheel base, front and rear track, and so on) obtained by a $K \& C$ test on a commercial pickup truck of medium payload. Figure 9 illustrates some of the physical parameters used in the vehicle model characterization in CarSim; more parameters and data curves used in the vehicle customization are in [33].

In CarSim, the model was customized as a generic fullsize load vehicle model, which is used as Software-in-the-Loop (SiL) in a Matlab/Simulink environment. The customization of the suspension system considers independent wheel stations at the front side and a rear solid axle at the back. Since CarSim is well accepted in the automotive control community (research and manufacturing), the customized model is a very useful tool to analyze the vehicle dynamics and evaluate the performance of the proposed control prototype.

Two simulation tests have been used to evaluate the performance of the AVCS. In both tests, an oil leakage with $\alpha=0.5$ at $t=0$ has been implemented in the MR damper of the front-left corner of the vehicle.

Test \#1, Two Bumps in Series. The vehicle is driven straightforwardly at constant speed of $v_{x}=30 \mathrm{Km} / \mathrm{h}$. The road profile is composed of two bumps in series of $5 \mathrm{~cm}$ height, Figure 10(a). This test allows studying the AVCS performance when the vehicle is driven over abrupt (sudden) road disturbances.

Figure 11 shows the performance of the proposed AVCS versus an uncontrolled suspension (US), considered as a passive system, and versus a controlled suspension that does not include the adaptation strategy to the fault (LPV nominal control, LPV NC); SFF (Suspension Free of Faults) refers to the simulation of the $\mathrm{LPV} / \mathrm{H}_{\infty}$ suspension control when no fault is considered. By using the Root Mean Square (RMS) value of the pitch rate $(\dot{\phi})$, sprung mass acceleration $\left(\ddot{z}_{s_{c}}\right)$, and heave $\left(z_{s_{c}}\right)$ motion of the vehicle as comfort performance indexes, normalized with respect to the uncontrolled suspension, the proposed AVCS improves $\dot{\phi} 28 \%, \ddot{z}_{s_{c}} 17 \%$, and $z_{s_{c}} 9 \%$. Note that the LPV nominal control has better comfort performance than US; however, the AVCS improves the comfort up to $10 \%$ when a damper fault occurs in comparison to the LPV NC.

Test \#2, Bounce Sine Sweep (BSS) Test. Chirp road sequence with decreasing road elevation $(10$ to $1 \mathrm{~cm})$ and span of frequency $(0.5$ to $10 \mathrm{~Hz})$ : the vehicle velocity is $30 \mathrm{Km} / \mathrm{h}$, Figure 10(b). This test allows the excitation of the automobile suspension system in the frequency band of interest for ride comfort. The test allows the monitoring of the vehicle behavior at each particular frequency in contrast to a random standard road profile (ISO 8608).

Figure 12 illustrates the pitch angle and the chassis vertical acceleration as performance indexes of comfort. In both signals, the AVCS has better comfort performance than the LPV NC: improvement of $24 \%$ in the pitch angle and $10 \%$ in the chassis vertical acceleration according to the RMS index. With respect to the US, the AVCS increases 


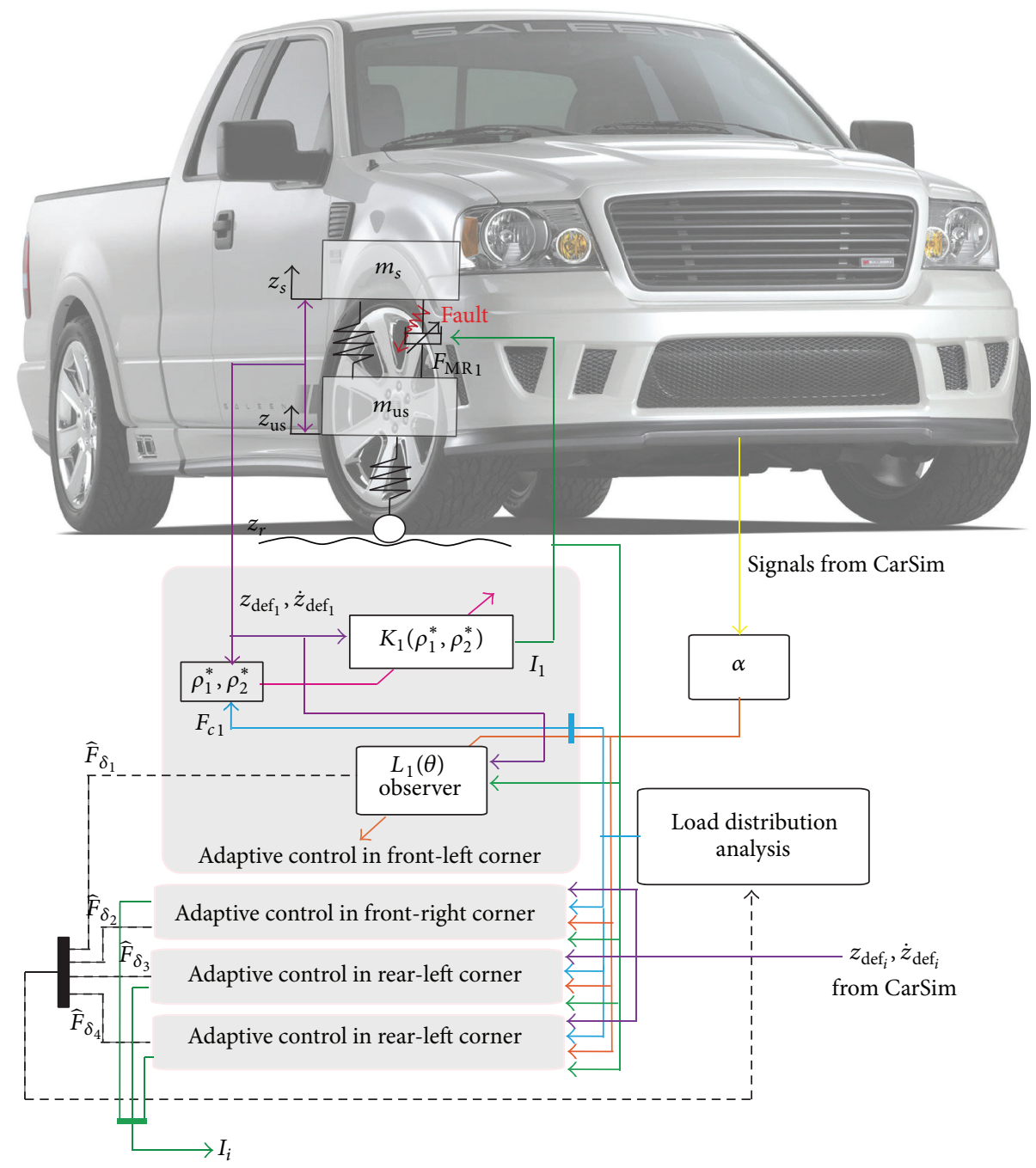

FIGURE 8: Adaptive suspension control system for MR damper faults.

the passenger comfort up to $64 \%$. Indeed in both signals, the AVCS presents similar comfort performance than the SFF case; see bar graphs in Figure 12. Qualitatively, the US has the worst comfort performance below the $15 \mathrm{~s}$ (from 0.5 to $5 \mathrm{~Hz}$ ), that is, around the first frequency of resonance of the chassis. Figure 12(b) shows that the main differences between AVCS and the nominal control are in the resonance frequencies; that is, the AVCS seeks to keep, as much as possible, the same vibrations like the SFF system, mainly in the natural frequencies of the suspension system.

Figure 13(a) shows how the MR damping force increases in a healthy damper, for example, at the front-right actuator, to compensate for the missing force of the faulty damper. The semiactiveness constraint of the MR damper is then ensured with the proposed AVCS. Figure 13(b) shows that the nominal LPV controller, whose performance is good when the suspension is free of faults, operates between 0 and $2 \mathrm{~A}$ without the compensation; when the compensation is used, the LPV controller utilizes the full range of actuation to generate more damping force and satisfies the saturation constraint of the MR damper.
Remark 2. The most important restriction to implement the proposed AVCS approach is the extra damping force available to compensate the lack of force caused by oil leakages. Mechanically, the semiactive damper must be designed with enough damping force (plus the nominal force used in the fault-free case) in order to have faculty to accommodate the lack of force of other faulty actuators.

In an implementation, the fault estimation and its compensation depend on the sample frequency. Usually, the most important bandwidth of control in automotive suspensions is from 0 to $25 \mathrm{~Hz}$, such that the microcontroller must use at least $100 \mathrm{~Hz}$ as sample frequency. Although at high car velocities the frequency of motion is greater than $20 \mathrm{~Hz}$, at these frequencies the vehicle body filters the road disturbances such that there is no difference in the vertical vehicle dynamics when a damper is faulty. Indeed, the fault estimation is frequency dependent such that the best frequency to estimate this malfunction is around the resonance frequency of the sprung mass [47]. 


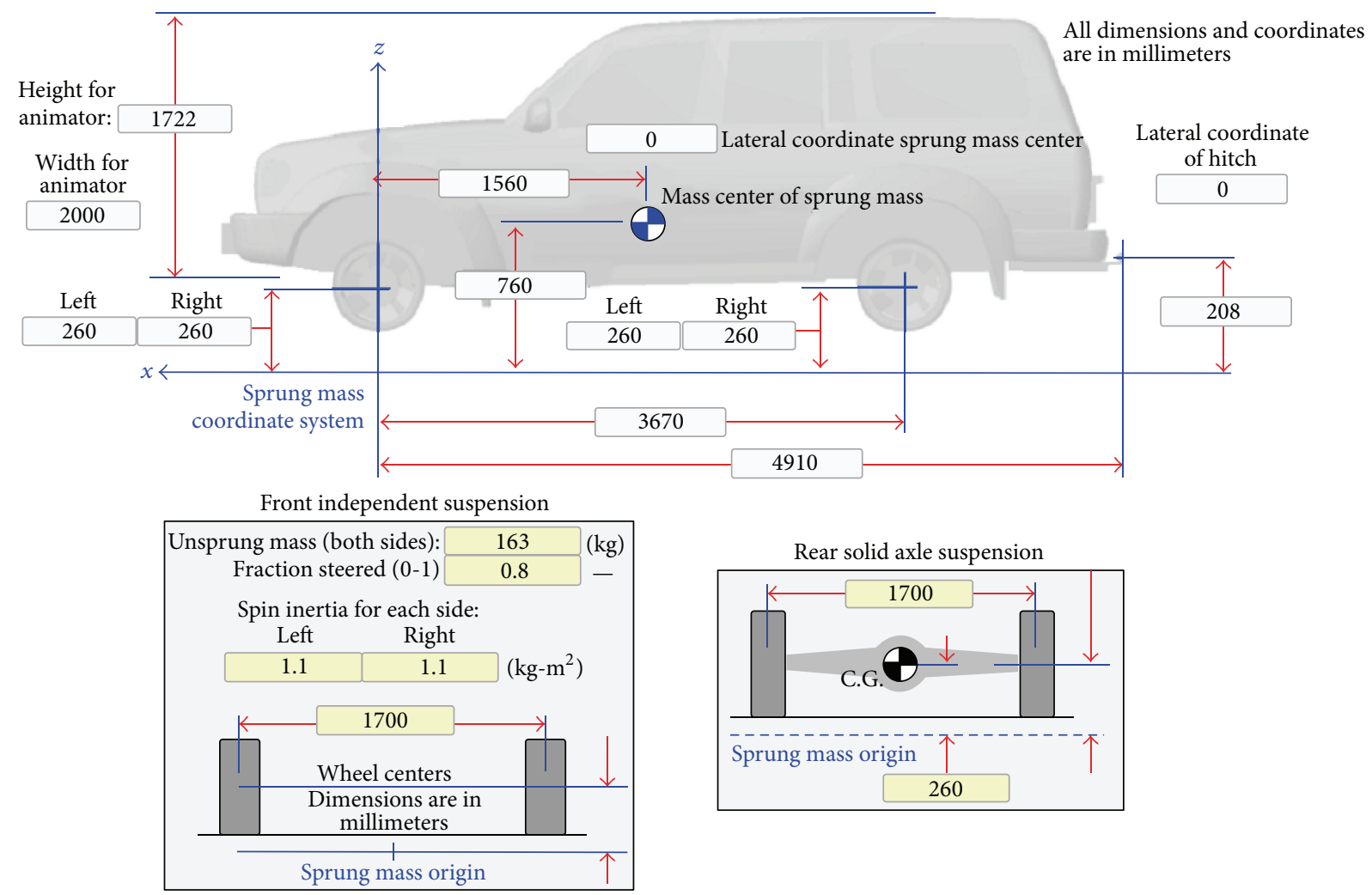

FIgure 9: Parameters for the pickup vehicle model in CarSim.

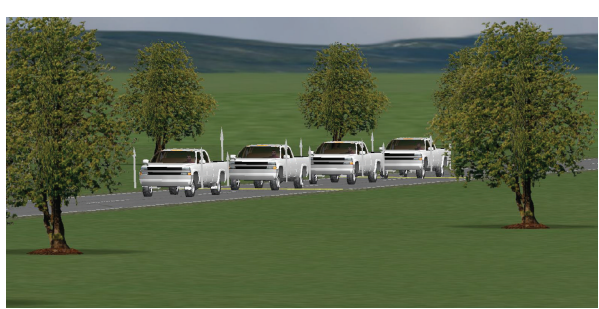

(a) Two bumps in series

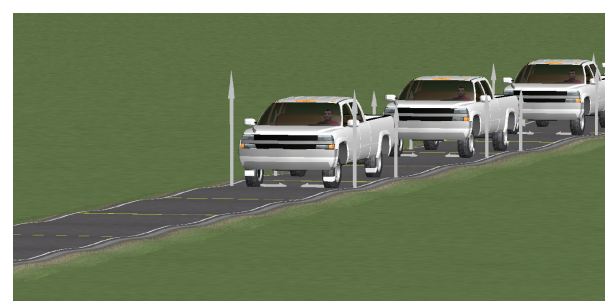

(b) BSS test

FIGURE 10: Simulation tests in CarSim used in the evaluation of the AVCS.

\section{Conclusions}

Based on a full vehicle suspension model, a new Adaptive Vibration Control System (AVCS) based on the Linear Parameter-Varying (LPV) control theory has been presented for a magnetorheological (MR) damper leakage. The main idea is to use the damping force of the remaining three healthy shock absorbers to avoid the fault propagation into the vertical dynamics of the vehicle; the control algorithm is two levels. Firstly the faulty Quarter of Vehicle (QoV) is isolated and the lack of force is estimated. Secondly, the load distribution analysis determines the compensation force that each healthy MR damper must add to reduce the effect of the lack of force of the faulty damper. This AVCS is based on the LPV framework to include the semiactiveness and saturation constraints of an MR damper into the controller design.
Inspired on the $H_{\infty}$ control problem, an LPV robust observer is proposed to estimate the missed force caused by an MR damper leakage; the polytopic LPV approach is used to solve a finite number of linear matrix inequalities where the leakage degree is a varying parameter, together with another varying parameter used to represent the MR nonlinearities. Simulation results show that this fault observer has good performance, with robustness to noisy measurements and road disturbances, in contrast with a static equation used to model the damping force obtained from the least squares estimation algorithm. The estimation error of the fault was decreased up to $20 \%$ in some frequencies using the fault observer. Indeed, the LPV observer can diagnose and estimate the faulty force caused by an abrupt or gradual damper leakage without considering the degree of the oil leakage.

Because the proposed Fault Detection and Isolation (FDI) system is based on a QoV model, four LPV robust observers 

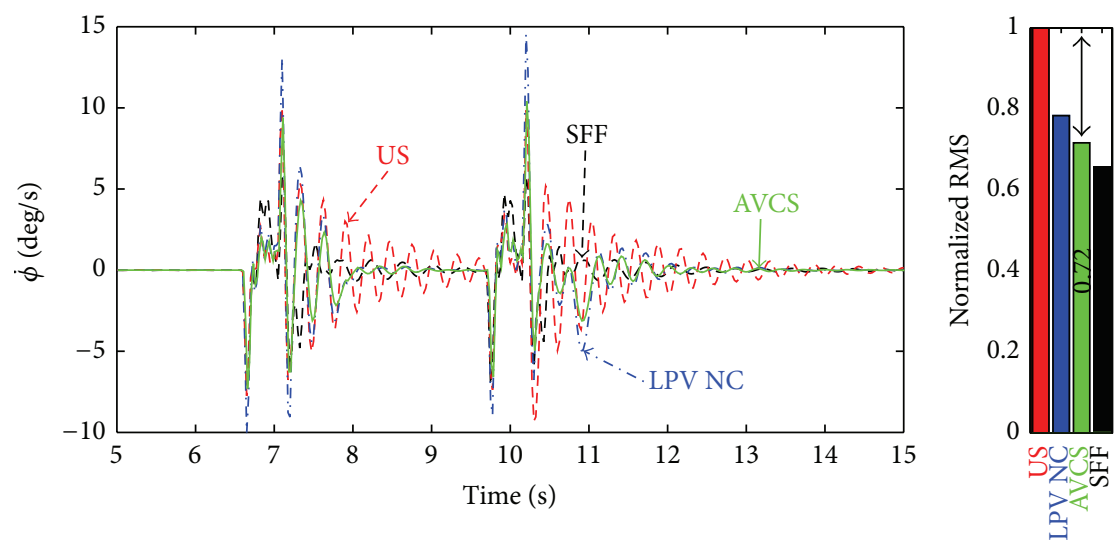

(a) Pitch rate
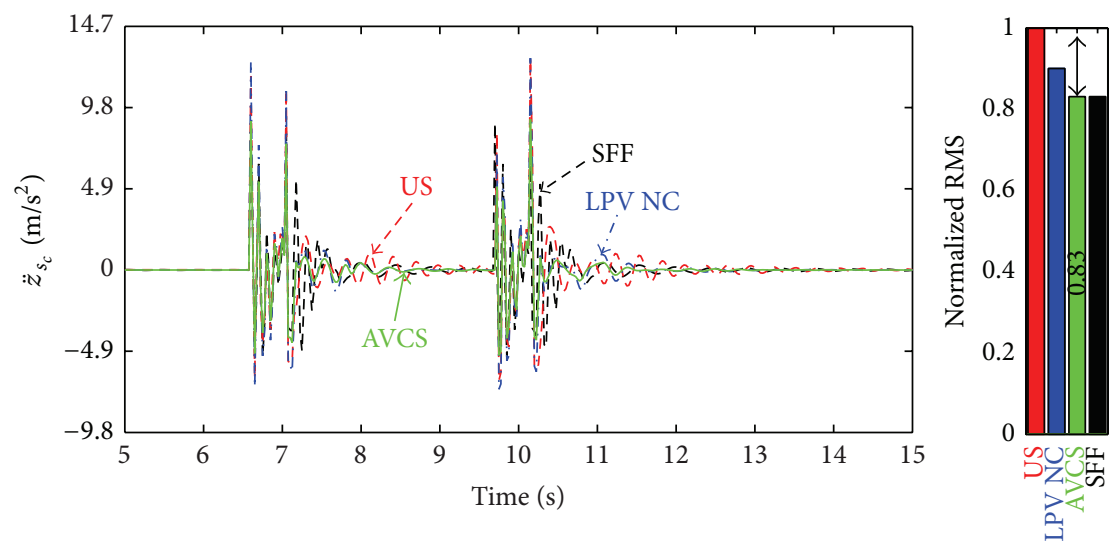

(b) Sprung mass acceleration
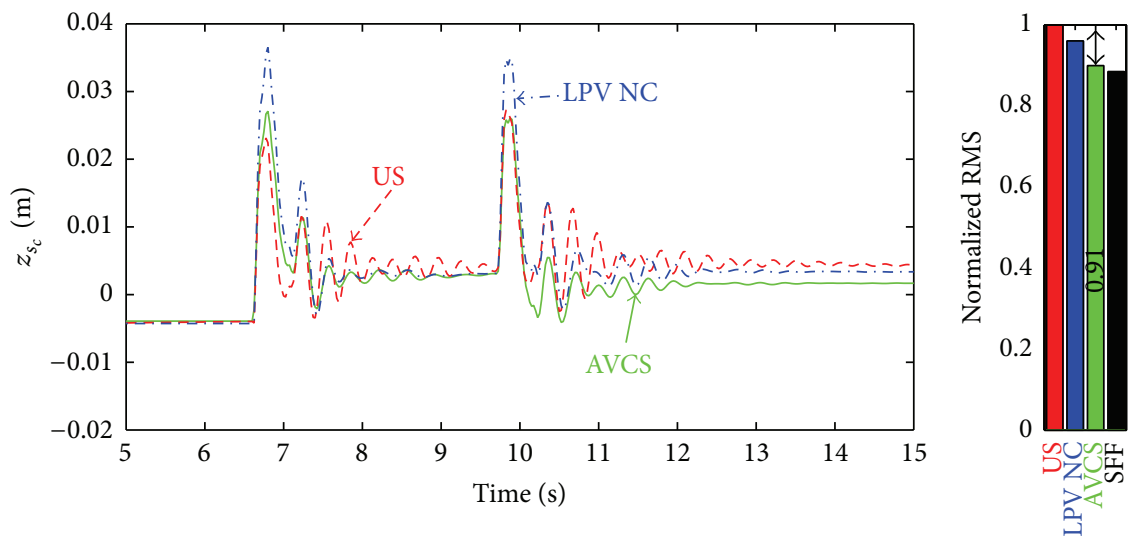

(c) Sprung mass position

FIGURE 11: Performance of the AVCS and comparison with other suspension systems in test \#1, by using a normalized RMS with respect to the uncontrolled suspension.

can be used to develop a global FDI strategy with independent corners. When a fault occurs in one vehicle corner, the associated observer estimates the lack of force caused by the damper leakage, which is used to compute the compensation forces that the healthy dampers must add. Simulation results in
CarSim, used as Software-in-the-Loop, show that when an oil leakage in the front-left MR damper is present the proposed AVCS improves the comfort up to $24 \%$ and $64 \%$ with respect to a nominal controlled (without fault compensation) and uncontrolled suspension system, respectively. 

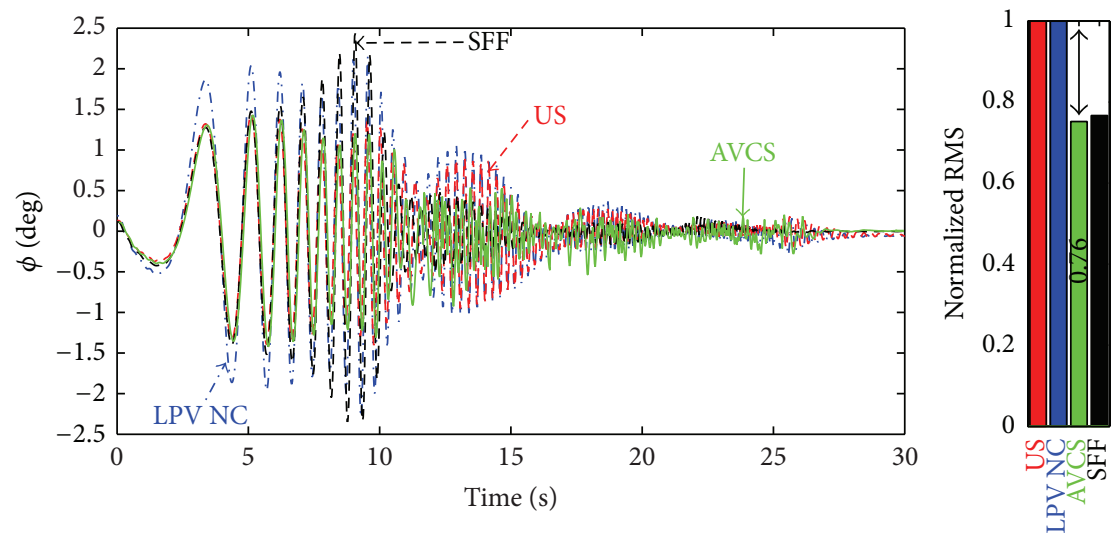

(a) Pitch angle
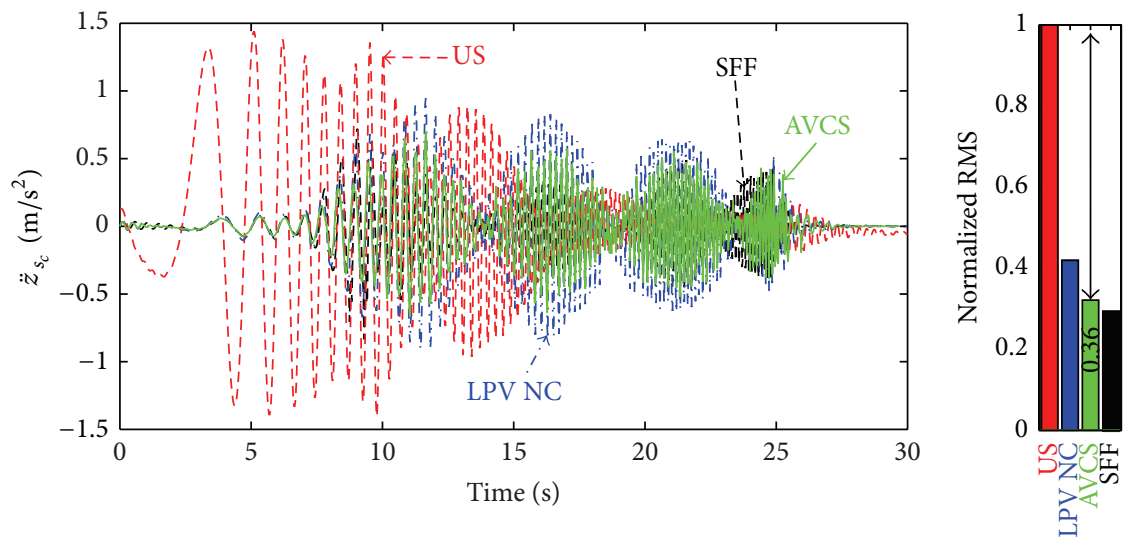

(b) Sprung mass acceleration

FIGURE 12: Performance of the AVCS and comparison with other suspension systems in test \#2, by using a normalized RMS with respect to the uncontrolled suspension.

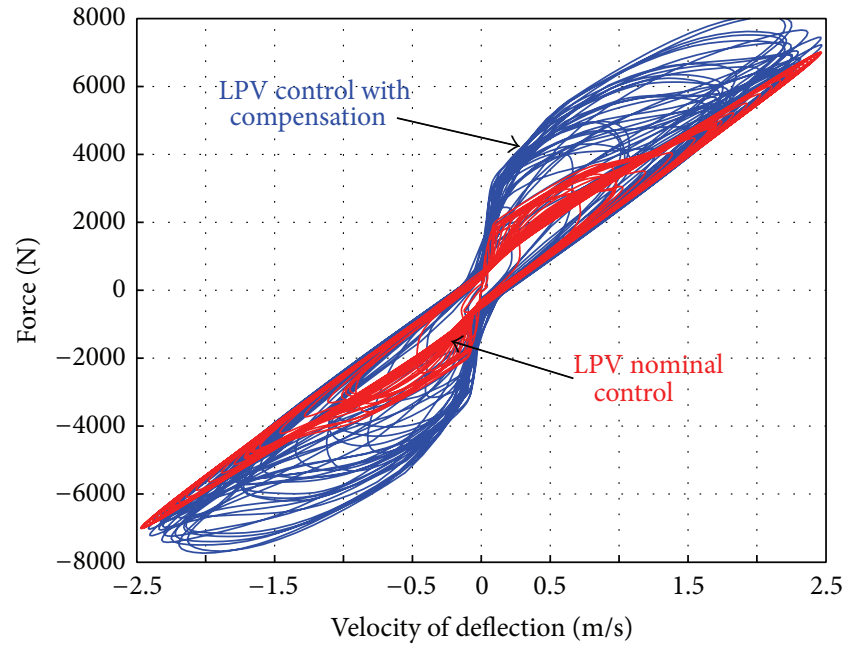

(a) FV diagram

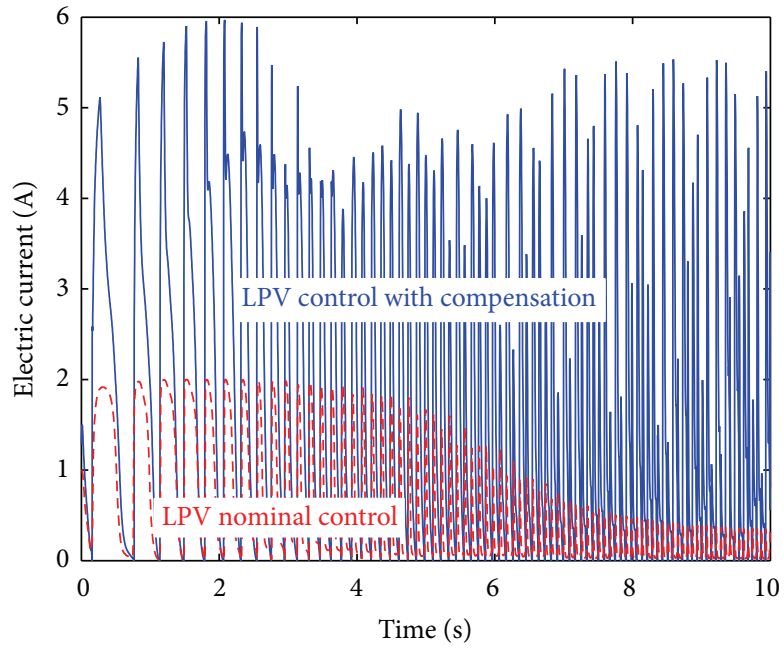

(b) Controller output

FIGURE 13: (a) Semiactive damping force in the front-right corner with and without fault compensation and (b) the corresponding controller output. 


\section{Abbreviations}

\begin{tabular}{|c|c|}
\hline$\alpha:$ & $\begin{array}{l}\text { Ratio of the faulty force and the } \\
\text { nominal force }\end{array}$ \\
\hline$\zeta_{i}:$ & $\begin{array}{l}\text { Damping factor of a second order filter } \\
\text { (weighting function) }\end{array}$ \\
\hline$\theta, \dot{\theta}$, and $\ddot{\theta}:$ & $\begin{array}{l}\text { Roll angle, roll rate, and roll } \\
\text { acceleration }\left(\mathrm{rad}, \mathrm{rad} / \mathrm{s} \text {, and } \mathrm{rad} / \mathrm{s}^{2}\right)\end{array}$ \\
\hline$\rho_{1}:$ & Nonlinear part of the damper model \\
\hline$\phi, \dot{\phi}$, and $\ddot{\phi}:$ & $\begin{array}{l}\text { Pitch angle, pitch rate, and pitch } \\
\text { acceleration }\left(\mathrm{rad}, \mathrm{rad} / \mathrm{s}, \text { and } \mathrm{rad} / \mathrm{s}^{2}\right)\end{array}$ \\
\hline$\Sigma(\theta)$ & $\begin{array}{l}\text { Generalized LPV plant in an } H_{\infty} \\
\text { control problem }\end{array}$ \\
\hline$\omega_{i}:$ & $\begin{array}{l}\text { Cut-frequency of the filter (weighting } \\
\text { function) }(\mathrm{rad} / \mathrm{s})\end{array}$ \\
\hline$a_{1}, a_{2}:$ & $\begin{array}{l}\text { Preyield viscous damping coefficients of } \\
\text { Guo model }(\mathrm{s} / \mathrm{m}, 1 / \mathrm{m})\end{array}$ \\
\hline$b_{1}:$ & $\begin{array}{l}\text { Viscous damping coefficient of Guo } \\
\text { model (Ns/m) }\end{array}$ \\
\hline$b_{2}:$ & $\begin{array}{l}\text { Stiffness coefficient of Guo model } \\
(\mathrm{N} / \mathrm{m})\end{array}$ \\
\hline$e:$ & Estimation error of the fault $(\mathrm{N})$ \\
\hline$f_{c}:$ & Dynamic yield force of Guo model (N) \\
\hline$F_{\delta}:$ & Loss of force $(\mathrm{N})$ \\
\hline$F_{\mathrm{MR}}:$ & Force of an MR (healthy) damper (N) \\
\hline $\bar{F}_{\mathrm{MR}}:$ & Force of a faulty MR damper $(\mathrm{N})$ \\
\hline$I:$ & $\begin{array}{l}\text { Control effort of an MR damper } \\
\text { (electric current) (A) }\end{array}$ \\
\hline$I_{x x}, I_{y y}:$ & Roll and pitch inertia $\left(\mathrm{Kg} \cdot \mathrm{m}^{2}\right)$ \\
\hline$K(\rho):$ & LPV controller \\
\hline$k_{s}:$ & Spring stiffness in a QoV $(\mathrm{N} / \mathrm{m})$ \\
\hline$k_{t}:$ & Tire stiffness in a QoV $(\mathrm{N} / \mathrm{m})$ \\
\hline$L(\theta):$ & LPV fault observer \\
\hline$l_{f}:$ & $\begin{array}{l}\text { Distance from center of gravity (CoG) to } \\
\text { front track }(\mathrm{m})\end{array}$ \\
\hline$l_{r}:$ & Distance from CoG to rear track (m) \\
\hline$m_{s}:$ & Sprung mass in a QoV (Kg) \\
\hline$m_{s_{c}}:$ & Total sprung mass (chassis mass) (Kg) \\
\hline$m_{u s}{ }^{c}:$ & Unsprung mass in a QoV $(\mathrm{Kg})$ \\
\hline$t_{f}:$ & Distance from CoG to front-left tire (m) \\
\hline$t_{r}:$ & Distance from CoG to rear-left tire (m) \\
\hline$v_{x}:$ & $\begin{array}{l}\text { Longitudinal vehicle velocity }(\mathrm{m} / \mathrm{s} \text {, } \\
\mathrm{Km} / \mathrm{h})\end{array}$ \\
\hline$W_{i}:$ & Weighting function \\
\hline$z_{\mathrm{def}}, \dot{z}_{\mathrm{def}}:$ & $\begin{array}{l}\text { Displacement and velocity of the } \\
\text { damper piston in a QoV }(\mathrm{m}, \mathrm{m} / \mathrm{s})\end{array}$ \\
\hline$z_{\infty}:$ & $\begin{array}{l}\text { Controlled variables in an } H_{\infty} \text { control } \\
\text { problem }\end{array}$ \\
\hline$z_{r}:$ & Road profile (m) \\
\hline$z_{s}, \dot{z}_{s}$, and $\ddot{z}_{s}:$ & $\begin{array}{l}\text { Sprung mass displacement, velocity, and } \\
\text { acceleration in a QoV }(\mathrm{m}, \mathrm{m} / \mathrm{s} \text {, and } \\
\left.\mathrm{m} / \mathrm{s}^{2}\right)\end{array}$ \\
\hline$z_{s_{c}}, \dot{z}_{s_{c}}$, and $\ddot{z}_{s_{c}}:$ & $\begin{array}{l}\text { Chassis displacement, velocity, and } \\
\text { acceleration in the CoG }(\mathrm{m}, \mathrm{m} / \mathrm{s} \text {, and } \\
\left.\mathrm{m} / \mathrm{s}^{2}\right)\end{array}$ \\
\hline$z_{u s}, \dot{z}_{u s}$, and $\ddot{z}_{u s}:$ & $\begin{array}{l}\text { Unsprung mass displacement, velocity, } \\
\text { and acceleration in a QoV }(\mathrm{m}, \mathrm{m} / \mathrm{s} \text {, and } \\
\left.\mathrm{m} / \mathrm{s}^{2}\right) \text {. }\end{array}$ \\
\hline
\end{tabular}

\section{Conflict of Interests}

The authors declare that there is no conflict of interests regarding the publication of this paper.

\section{Acknowledgments}

The authors thank CONACyT (PCP Project 03/2010) for its partial support. Also, the authors thank Dr. Jorge de Jesús Lozoya-Santos for sharing his experience and knowledge to improve this paper along with some discussions; they thank him for his time.

\section{References}

[1] J. Dixon, The Shock Absorber Handbook, Wiley, 2nd edition, 2007.

[2] B. T. Fijalkowski, Automotive Mechatronics: Operational and Practical Issues, vol. 2, Springer, 2011.

[3] J. Lozoya-Santos, Control of automotive semiactive suspensions [Ph.D. thesis], Tecnológico de Monterrey, Campus Monterrey, 2013, chapter. 2-4.

[4] T. Gillespie, Fundamentals of Vehicle Dynamics, chapter 5, Society of Automotive Engineers, 1992.

[5] R. Stanway, J. L. Sproston, and N. G. Stevens, "Non-linear modelling of an electro-rheological vibration damper," Journal of Electrostatics, vol. 20, no. 2, pp. 167-184, 1987.

[6] D. R. Gamota and F. E. Filisko, "Dynamic mechanical studies of electrorheological materials: moderate frequencies," Journal of Rheology, vol. 35, no. 3, pp. 399-425, 1991.

[7] B. F. Spencer Jr., S. J. Dyke, M. K. Sain, and J. D. Carlson, "Phenomenological model for magnetorheological dampers," ASCE Journal of Engineering Mechanics, vol. 123, no. 3, pp. 230238, 1997.

[8] N. M. Wereley, L. Pang, and G. M. Kamath, "Idealized hysteresis modeling of electrorheological and magnetorheological dampers," Journal of Intelligent Material Systems and Structures, vol. 9, no. 8, pp. 642-649, 1998.

[9] G. Yang, B. F. Spencer Jr., J. D. Carlson, and M. K. Sain, "Largescale MR fluid dampers: modeling and dynamic performance considerations," Engineering Structures, vol. 24, no. 3, pp. 309$323,2002$.

[10] S.-B. Choi and S.-S. Han, " $H_{\infty}$ control of electrorheological suspension system subjected to parameter uncertainties," Mechatronics, vol. 13, no. 7, pp. 639-657, 2003.

[11] D. Guo and H. Hu, "Nonlinear stiffness of a magnetorheological damper," Nonlinear Dynamics, vol. 40, no. 3, pp. 241249, 2005.

[12] L. X. Wang and H. Kamath, "Modelling hysteretic behaviour in magnetorheological fluids and dampers using phase-transition theory," Smart Materials and Structures, vol. 15, no. 6, pp. 17251733, 2006.

[13] S. Guo, S. Yang, and C. Pan, "Dynamical modeling of magnetorheological damper behaviors," Journal of Intelligent Material Systems and Structures, vol. 17, pp. 3-14, 2006.

[14] N. M. Kwok, Q. P. Ha, T. H. Nguyen, J. Li, and B. Samali, "A novel hysteretic model for magnetorheological fluid dampers and parameter identification using particle swarm optimization," Sensors and Actuators A: Physical, vol. 132, no. 2, pp. 441-451, 2006. 
[15] Ş. Çeşmeci and T. Engin, "Modeling and testing of a fieldcontrollable magnetorheological fluid damper," International Journal of Mechanical Sciences, vol. 52, no. 8, pp. 1036-1046, 2010.

[16] V. S. Atray and P. N. Roschke, "Design, fabrication, testing, and fuzzy modeling of a large magnetorheological damper for vibration control in a railcar," in Proceedings of the IEEE/ASME Joint Rail Conference, pp. 223-229, Chicago, Ill, USA, April 2003.

[17] K. K. Ahn, M. A. Islam, and D. Q. Truong, "Hysteresis modeling of magneto-rheological (MR) fluid damper by self tuning fuzzy control," in Proceedings of the International Conference on Control, Automation and Systems (ICCAS '08), pp. 2628-2633, October 2008.

[18] A. C. Shivaram and K. V. Gangadharan, "Statistical modeling of a magneto-rheological fluid damper using the design of experiments approach," Smart Materials and Structures, vol. 16, no. 4, pp. 1310-1314, 2007.

[19] S.-B. Choi, S.-K. Lee, and Y.-P. Park, "A hysteresis model for the field-dependent damping force of a magnetorheological damper," Journal of Sound and Vibration, vol. 245, no. 2, pp. 375383, 2001.

[20] K.-S. Hong, H.-C. Sohn, and J. K. Hedrick, "Modified skyhook control of semi-active suspensions: a new model, gain scheduling, and hardware-in-the-loop tuning," Journal of Dynamic Systems, Measurement and Control, vol. 124, no. 1, pp. 158-167, 2002.

[21] H. Du, K. Y. Sze, and J. Lam, "Semi-active $H_{\infty}$ control of vehicle suspension with magneto-rheological dampers," Journal of Sound and Vibration, vol. 283, no. 3-5, pp. 981-996, 2005.

[22] C. Poussot-Vassal, O. Sename, L. Dugard, P. Gáspár, Z. Szabó, and J. Bokor, "A new semi-active suspension control strategy through LPV technique," Control Engineering Practice, vol. 16, no. 12, pp. 1519-1534, 2008.

[23] C.-C. Chang and L. Zhou, "Neural network emulation of inverse dynamics for a magnetorheological damper," Journal of Structural Engineering, vol. 128, no. 2, pp. 231-239, 2002.

[24] S. M. Savaresi, S. Bittanti, and M. Montiglio, "Identification of semi-physical and black-box non-linear models: the case of MR-dampers for vehicles control," Automatica, vol. 41, no. 1, pp. 113-127, 2005.

[25] H. Du, J. Lam, and N. Zhang, "Modelling of a magnetorheological damper by evolving radial basis function networks," Engineering Applications of Artificial Intelligence, vol. 19, no. 8, pp. 869-881, 2006.

[26] M. Zapateiro, N. Luo, H. R. Karimi, and J. Vehí, "Vibration control of a class of semiactive suspension system using neural network and backstepping techniques," Mechanical Systems and Signal Processing, vol. 23, no. 6, pp. 1946-1953, 2009.

[27] H. Metered, P. Bonello, and S. O. Oyadiji, “The experimental identification of magnetorheological dampers and evaluation of their controllers," Mechanical Systems and Signal Processing, vol. 24, no. 4, pp. 976-994, 2010.

[28] M. J. L. Boada, J. A. Calvo, B. L. Boada, and V. Díaz, "Modeling of a magnetorheological damper by recursive lazy learning," International Journal of Non-Linear Mechanics, vol. 46, no. 3, pp. 479-485, 2011.

[29] J. C. Tudón-Martínez, J. J. Lozoya-Santos, R. MoralesMenendez, and R. A. Ramirez-Mendoza, "An experimental artificial-neural-network-based modeling of magnetorheological fluid dampers," Smart Materials and Structures, vol. 21, no. 8, Article ID 085007, pp. 1-16, 2012.
[30] Sachs, "Shock absorbers leak, potential causes," Tech. Rep., Sachs, 2008.

[31] S. Fergani, O. Sename, and L. Dugard, "A LPV/ $\mathfrak{H}_{\infty}$ fault tolerant control of vehicle roll dynamics under semi-active damper malfunction," in Proceedings of the American Control Conference (ACC '14), pp. 4482-4487, IEEE, Portland, Ore, USA, June 2014.

[32] J. C. Tudón-Martínez, S. Varrier, O. Sename, R. MoralesMenendez, J.-J. Martinez, and L. Dugard, "Fault tolerant strategy for semi-active suspensions with LPV accommodation?" in Proceedings of the 2nd International Conference on Control and Fault-Tolerant Systems (SysTol' 13), pp. 631-636, Nice, France, October 2013.

[33] J. Tudón-Martínez, Fault tolerant control in automotive semiactive suspensions [Ph.D. thesis], Tecnológico de Monterrey, Campus Monterrey, Monterrey, Mexico, 2014.

[34] J. De-J Lozoya-Santos, R. Morales-Menendez, R. RamirezMendoza, J. C. Tudón-Martinez, O. Sename, and L. Dugard, "Magnetorheological damper-an experimental study," Journal of Intelligent Material Systems and Structures, vol. 23, no. 11, pp. 1213-1232, 2012.

[35] A. Yetendje, M. Seron, and J. De Doná, "Diagnosis and actuator fault tolerant control in vehicle active suspension," in Proceedings of the 3 rd International Conference on Information and Automation for Sustainability (ICIAFS '07), pp. 153-158, Melbourne, Australia, December 2007.

[36] A. Chamseddine and H. Noura, "Control and sensor fault tolerance of vehicle active suspension," IEEE Transactions on Control Systems Technology, vol. 16, no. 3, pp. 416-433, 2008.

[37] P. Gáspár, Z. Szabó, and J. Bokor, "LPV design of fault-tolerant control for road vehicles," in Proceedings of the 1st Conference on Control and Fault-Tolerant Systems (SysTol '10), pp. 807-812, Nice, France, October 2010.

[38] D. Fischer and R. Isermann, "Mechatronic semi-active and active vehicle suspensions," Control Engineering Practice, vol. 12, no. 11, pp. 1353-1367, 2004.

[39] J. Kim and H. Lee, "Sensor fault detection and isolation algorithm for a continuous damping control system," Journal of Automobile Engineering, vol. 225, no. 10, pp. 1347-1364, 2011.

[40] H. Wang and G. Song, "Fault detection and fault tolerant control of a smart base isolation system with magneto-rheological damper," Smart Materials and Structures, vol. 20, no. 8, Article ID 085015, 9 pages, 2011.

[41] Y. Vidal, L. Acho, F. Pozo, and J. Rodellar, "Fault detection in base-isolation systems via a restoring force observer," in Proceedings of the Conference on Control and Fault-Tolerant Systems (SysTol '10), pp. 777-782, IEEE, Nice, France, October 2010.

[42] C. Scherer, P. Gahinet, and M. Chilali, "Multiobjective outputfeedback control via LMI optimization," IEEE Transactions on Automatic Control, vol. 42, no. 7, pp. 896-911, 1997.

[43] P. Gahinet, P. Apkarian, and M. Chilali, "Affine parameterdependent Lyapunov functions and real parametric uncertainty," IEEE Transactions on Automatic Control, vol. 41, no. 3, pp. 436-442, 1996.

[44] S. Savaresi, C. Poussot-Vassal, C. Spelta, O. Sename, and L. Dugard, Semi-Active Suspension Control for Vehicles, Elsevier, Butterworth-Heinemann, 2010.

[45] A.-L. Do, O. Sename, and L. Dugard, "LPV modeling and control of semi-active dampers in automotive systems," in Control of Linear Parameter Varying Systems with Applications, J. Mohammadpour and C. W. Scherer, Eds., pp. 381-411, Springer, New York, NY, USA, 2012. 
[46] P. Apkarian and P. Gahinet, "A convex characterization of gainscheduled $H_{\infty}$ controllers," IEEE Transactions on Automatic Control, vol. 40, no. 5, pp. 853-864, 1995.

[47] J. Lozoya-Santos, J. Tudón-Martínez, R. Morales-Menendez, R. Ramírez-Mendoza, and L. Garza-Castañón, "A fault detection method for an automotive magneto-rheological damper," in Proceedings of the 8th IFAC International Symposium on Fault Detection, Supervision and Safety for Technical Processes, pp. 1209-1214, Mexico City, Mexico, 2012. 

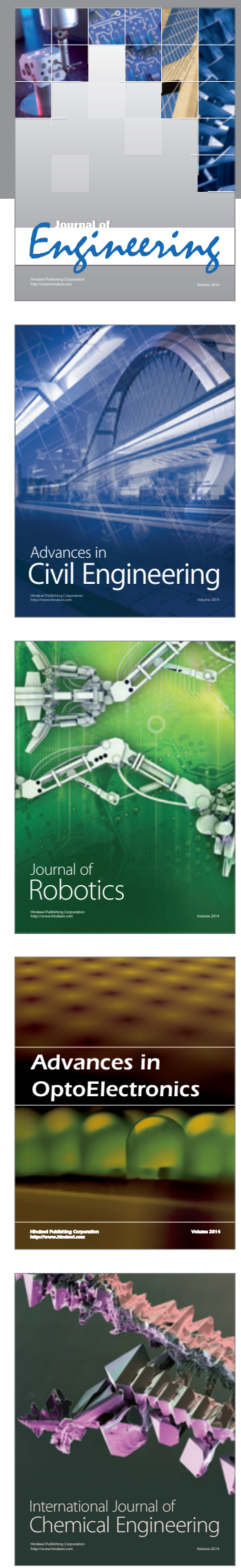

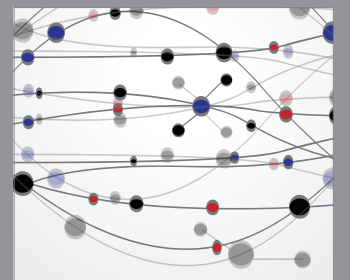

The Scientific World Journal
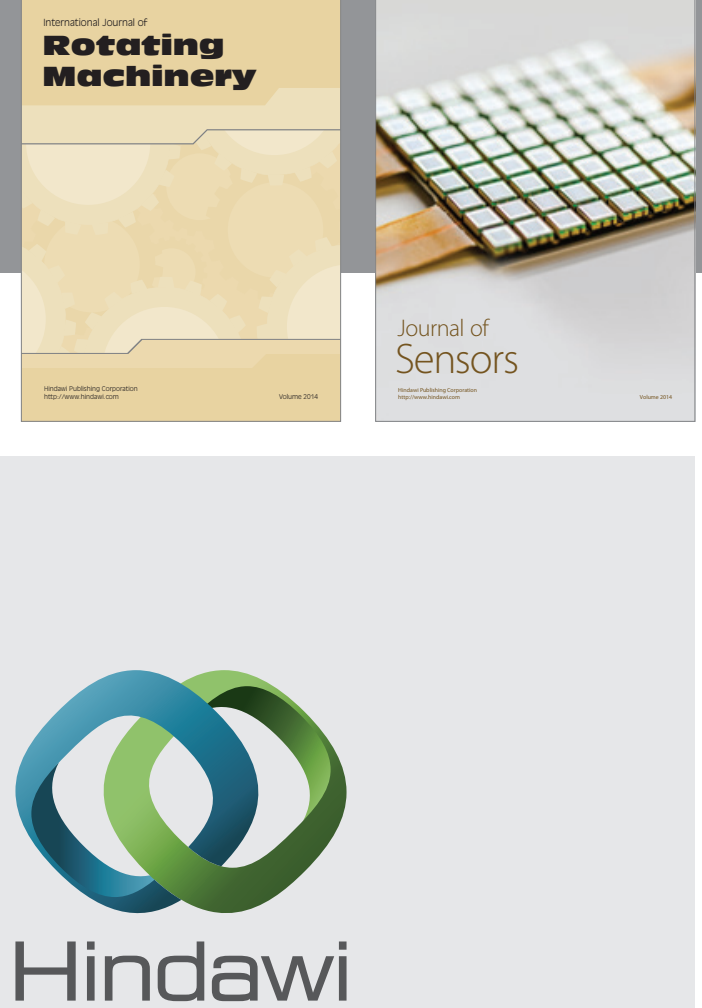

Submit your manuscripts at http://www.hindawi.com
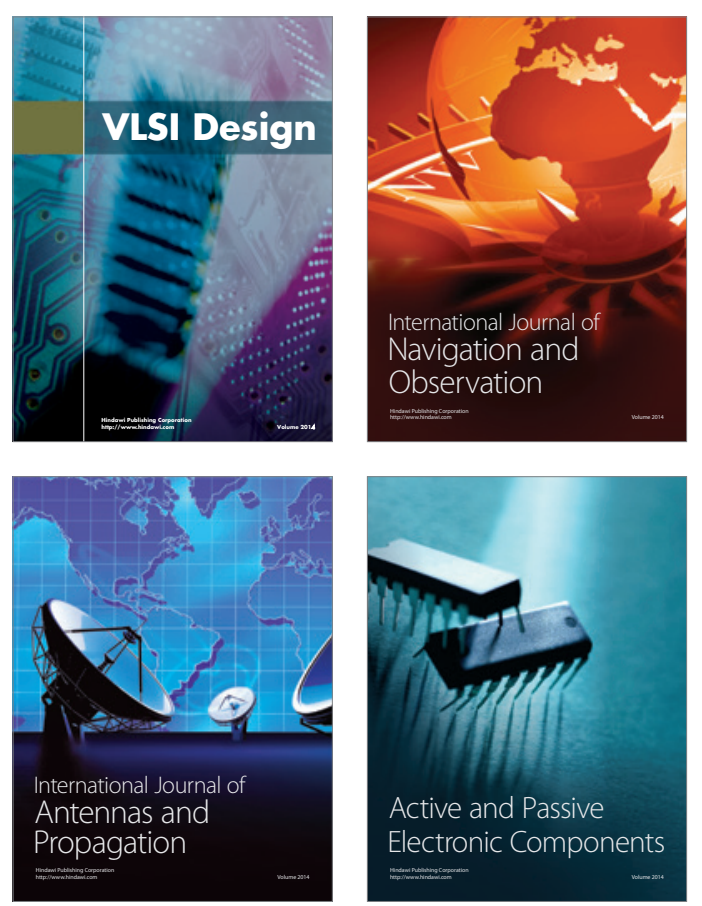
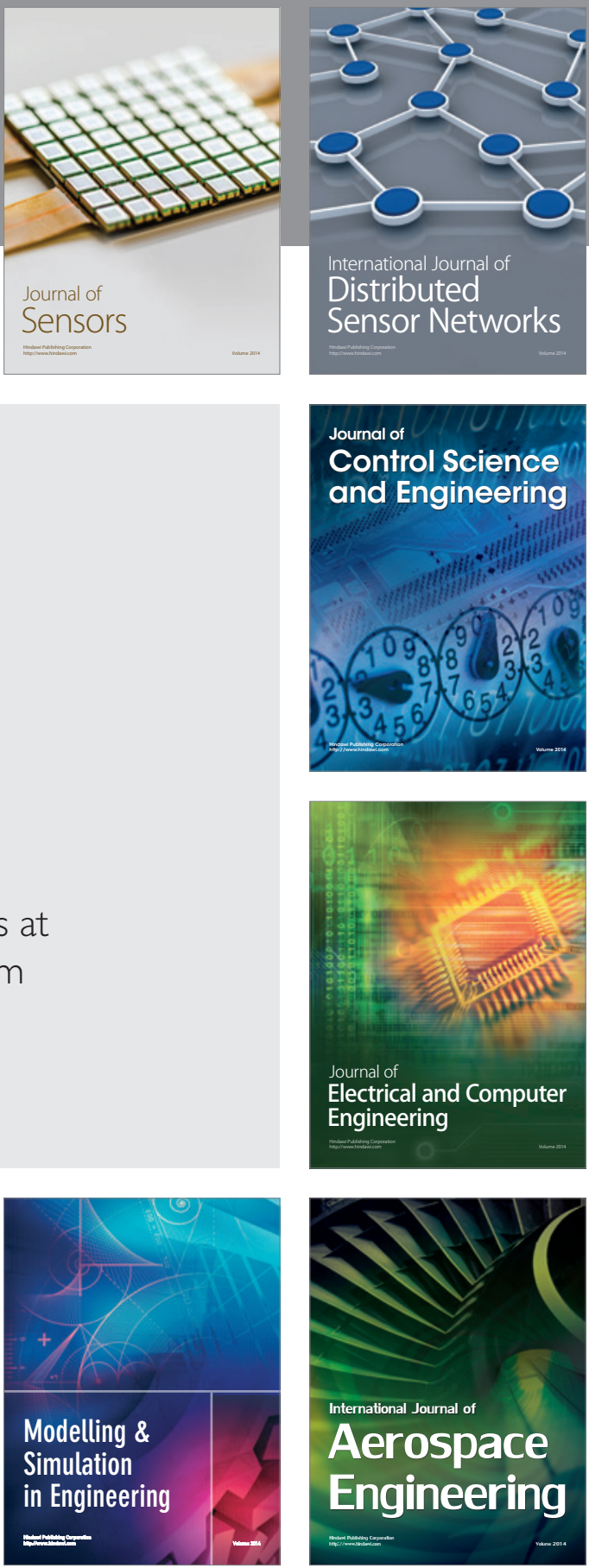

Journal of

Control Science

and Engineering
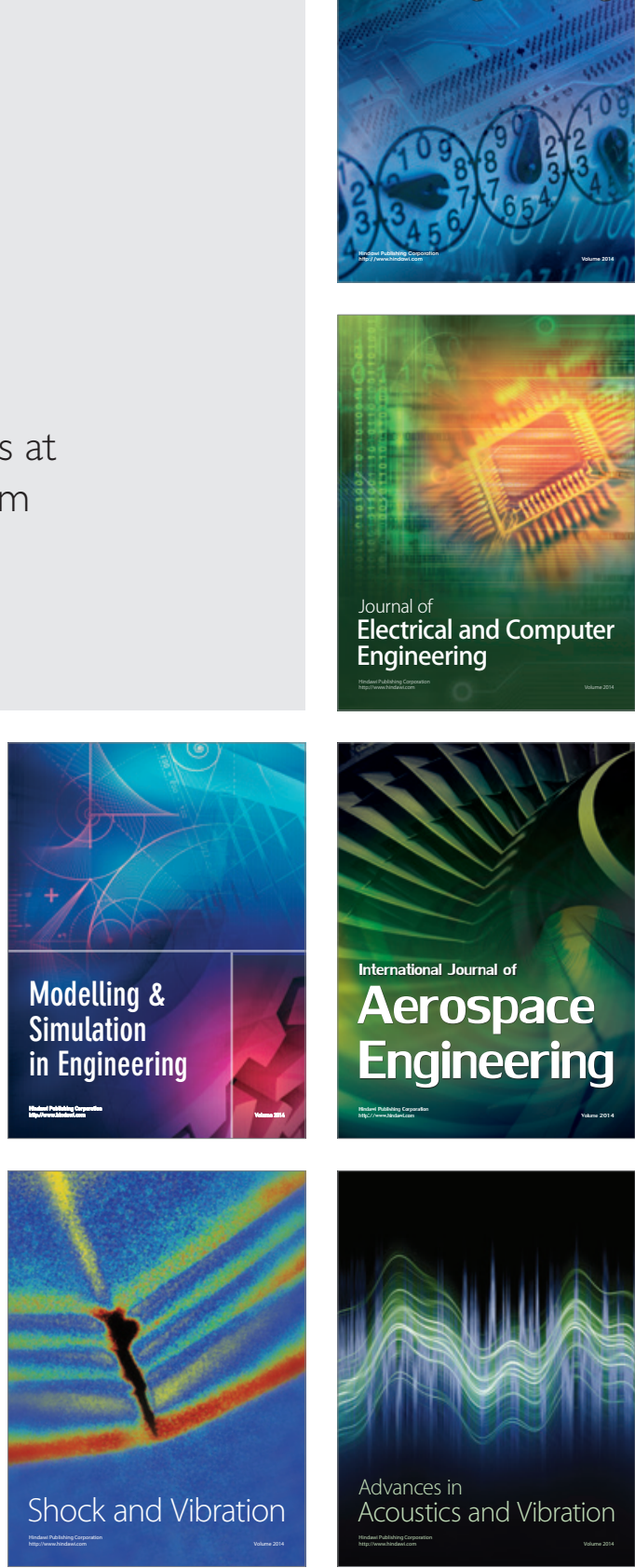